\title{
The modulating influence of convectively coupled equatorial waves (CCEWs) on the variability of tropical precipitation
}

\author{
Sandro Wellyanto Lubis ${ }^{\dagger *}$ and Christoph Jacobi \\ Institute of Meteorology, University of Leipzig, Germany
}

\begin{abstract}
A detailed examination of the Tropical Rainfall Measuring Mission (TRMM) daily estimates, merging high-quality (HQ)/infrared (IR) precipitation from 1998 to 2009, revealed the modulating influence of convectively coupled equatorial waves (CCEWs), including Kelvin, $n=1$ equatorial Rossby (ER), mixed Rossby-gravity (MRG), and tropical depression (TD)-type waves, on the variability of tropical precipitation. Consistent with inviscid $\beta$-plane shallow water theory, the wave-induced convergence zones are found to be an active location for precipitation. Modulated precipitation by ER waves exhibits slow westward phase progression of approximately $-4.8 \mathrm{~m} \mathrm{~s}^{-1}$, and it is distributed as a symmetric pair of off-equatorial maxima and a weak equatorial peak. MRG waves show an asymmetrically modulated precipitation distribution and a faster phase progression of about $-16.1 \mathrm{~m} \mathrm{~s}^{-1}$ followed by enhanced symmetrical gyres. Peak precipitation within TD-type waves originates in the trough axis of off-equatorial vortex trains and propagates to the west at approximately -9.5 $\mathrm{m} \mathrm{s}^{-1}$. Regarding Kelvin waves, typical positive precipitation anomalies travelling in the east-west direction occur in the maxima of low-level wind convergences, with an approximate phase progression of about $15.4 \mathrm{~m} \mathrm{~s}^{-1}$.

Variability of tropical precipitation due to CCEWs behaves relatively varied over different seasons and locations. TD-type waves exhibit more predominant impacts than other waves, with maximum impacts of up to $9.75 \pm 4.54 \%$ of the total precipitation variance during boreal summer, which is three times higher than the MRG peak $(2.90 \pm 0.82 \%)$. On the other hand, Kelvin and $n=1$ ER waves each have more prominent effects during boreal winter; up to $6.99 \pm 3.30 \%$ and $3.77 \pm 1.79$ $\%$, respectively. On average, our results suggest that, although being less dominant than other tropical oscillations (e.g. ENSO, MJO), these four types of CCEWs can considerably affect precipitation by contributing up to 16-20\% of the total intraseasonal (2.5-72 days) precipitation variance in the tropics.
\end{abstract}

KEY WORDS CCEWs; Kelvin waves; MRG waves; $n=1$ Rossby waves; TD-type waves; tropical precipitation; TRMM

Received 30 September 2013; Revised 25 April 2014; Accepted 9 May 2014

\section{Introduction}

Tropical convective systems are preferentially modulated by individual modes of tropical waves (e.g., Takayabu, 1994; Wheeler and Kiladis, 1999 (hereafter referred to as WK99); Roundy and Frank, 2004 (hereafter referred to as RF04); Kiladis et al., 2009). In turn, convection generates a wide-reaching spectrum of waves that either circumnavigate the globe or propagate vertically to the middle atmosphere (e.g. Lindzen, 1974, 2003; Masunaga, 2009). This coupling mechanism exhibits a prominent influence on the large-scale synoptic systems and is commonly referred to as convectively coupled equatorial waves (CCEWs) (WK99). Interaction between tropospheric equatorial waves and convection may result in unique spatial distributions and frequency characteristics of tropical precipitation. Moreover, vertical propagation of CCEWs into the middle atmosphere may have a significant impact

\footnotetext{
* Correspondence to: S. W. Lubis, GEOMAR Helmholtz Centre for Ocean Research Kiel, Düsternbrooker. 20, 24105 Kiel, Germany. E-mail: slubis@geomar.de

†Current address: GEOMAR Helmholtz Centre for Ocean Research Kiel, Düsternbrooker. 20, 24105 Kiel, Germany.
}

on the dynamical troposphere-stratosphere coupling (e.g. Kawatani et al., 2009; Yang et al., 2011).

The main role of CCEWs has been widely found to be a strong influence on the predominant variability of tropical weather and the dynamics of the climate system. Owing to CCEWs importance to the tropical atmosphere, considerable efforts have been made extensively to understand their behaviour through both observations and model studies. Most investigations were carried out with numerous datasets, which often employ the outgoing longwave radiation (OLR, WK99), precipitable water (PW, RF04), Tropical Rainfall Measuring Mission (TRMM) precipitation estimates (e.g. Cho et al., 2004; Sobel et al., 2004), brightness temperature (e.g. Yang et al., 2003; Kiladis et al., 2009; Huang and Huang, 2011), and upper tropospheric water vapour (UTWV, Schreck et al., 2013). Substantial roles of CCEWs in driving the dynamics of lower and middle atmosphere from the previous studies can be summarized as follows: (1) CCEWs control the intensity and timing of precipitation over the tropics (e.g. Cho et al., 2004; Masunaga et al., 2006; Mekonnen et al., 2006; Mounier et al., 2007; Kim and Alexander, 2013); (2) CCEWs, particularly the mixed Rossby-gravity (MRG), equatorial Rossby (ER), and tropical depression 
(TD)-type waves, intensely support the development of tropical cyclone (TC) genesis by enhancing the lower-level vertical vorticity of the local circulation (e.g. Dickinson and Molinari, 2002; Frank and Roundy, 2006; Schreck etal., 2012); (3) coupling between CCEWs and dry equatorial waves in the upper troposphere and lower stratosphere (UTLS) plays a vital role in modulating the background zonal winds by depositing easterly or westerly momentum from the troposphere into the stratosphere [wave-mean flow interaction, e.g. Quasi-Biennial Oscillation (QBO)] (e.g. Yang et al., 2011, 2012); (4) vertical propagation of CCEWs substantially drives the stratospheric transport circulation (e.g. Yang et al., 2011; Maury et al., 2013); and (5) teleconnection between CCEWs and middle/high latitude dynamics is advantageous in predicting long-range outcomes at higher latitudes or long-term changes in extratropical weather patterns (e.g. Hoskins and Yang, 2000; Gloeckler and Roundy, 2013; Schreck et al., 2013).

Tropical precipitation variability in accordance with the spectral signature of CCEWs has been evaluated in some recent studies, covering submonthly, synoptic, and intraseasonal timescales (Cho et al., 2004; Sobel et al., 2004; Lin et al., 2006; Masunaga et al. 2006; Mounier et al., 2007; Kim and Alexander, 2013). Most results showed that the coupling of convection with the equatorial waves led to unique frequency characteristics in tropical precipitation. Cho et al. (2004) observed peaks in high-resolution TRMM $3 \mathrm{G} 68$ precipitation data that indicated the definitive existence of CCEWs, including Kelvin waves, $n=1 \mathrm{ER}$, MRG, and TD-type waves. Their study achieved a better understanding of pronounced CCEW signatures within precipitation datasets, and qualitatively showed that coupling mechanisms between cumulus convection and equatorial waves considerably control the intraseasonal variability of tropical precipitation. However, the underlying physical mechanism has not yet been addressed more closely. Sobel et al. (2004) in the TRMM Kwajalein experiment also demonstrated that some precipitation events during the experiment were associated with the passage of Kelvin waves. The other individual modes of the tropical oscillations (e.g. MRG and TD-type wave) were also shown to have a prominent role in organizing local precipitation activity. Masunaga et al. (2006) utilizing TRMM precipitation radar (PR) and visible/infrared scanner (VIRS) further documented the potential relationship between CCEWs (including $n=1$ ER and Kelvin waves) and the dominant intraseasonal Madden-Julian Oscillation (MJO) in modulating the precipitation. They documented how the interaction between Kelvin waves and ER waves within the MJO convective envelope may be linked to off-equatorial boundary layer convergence, especially when it is at its maximum during boreal winter.

Kim and Alexander (2013) extended the investigation of the CCEW influence to including the submonthly variability of tropical precipitation, using TRMM and five Reanalysis product datasets. They reported that the variability of tropical precipitation due to low frequency
CCEWs is relatively varied over different geographical areas. The westward high variance (frequency $>1 / 3$ cycle per day) is more pronounced in affecting the precipitation variability for all seasons in Africa, while the strong precipitation variance over the Pacific Ocean is dominated by westward high frequency waves which are largely related to enhanced inertio gravity (IG) and TD-type wave activity during boreal summer. MJO activities, on the other hand, are observed to considerably influence the precipitation variability over the Maritime Continent. Nevertheless, the broad scope of their study focused chiefly on the assessment of the reanalysis products to resolve the CCEWs, as a crucial parameter in the tropical atmospheric models. The representation of particular single wave modes affecting precipitation variability was merely described in general way. The waves were not isolated specifically, and therefore the wave spectra with different dispersive properties became mixed up, and their values were inadvertently combined.

By detailed analysis of the interaction between waves and convection, this study intends to contribute to a comprehensive understanding of the CCEW effect on the precipitation variability over the entire tropical region. To this end, a modified space-time filtering is employed to eliminate noise contamination within a wave's spectral band, and to avoid undesirable spectral mixtures among the modes. Total variance as a product of inverted field filtering at a given filter band was calculated to quantify the portion of modulated precipitation variance attributed to CCEW activities. Furthermore, time-lagged composite analysis is used to characterize the evolution of perturbation convective and dynamic signals over time. The main objectives of this work are addressed in the following questions:

1. How does precipitation in nature behave under the influence of CCEWs?

2. What percentage of tropical precipitation variability can be attributed to the more divergent (Kelvin wave) and more rotational ( $n=1 \mathrm{ER}$, MRG, and TD-type wave) types of CCEWs in different seasons and geographical locations?

The remainder of the paper is organized as follows. The datasets and methods used are described in Section 2. Section 3 presents the behaviours of modulated precipitation through time-lagged composite analysis for each CCEW. The geographic distribution and seasonal variation attributed to the CCEW activities are investigated in Section 4. Finally, summary and concluding remarks are offered in Section 5.

\section{Data and methods}

\subsection{Data}

Three sets of observational data were used to examine the modulating influence of CCEWs on the tropical precipitation: (1) the TRMM 3B42 version-6 daily satellite-based estimates (Huffman et al., 2007); (2) OLR from the 
National Oceanic and Atmospheric Administration (NOAA) and the National Environmental Satellite Data and Information Service (NESDIS) (Liebmann and Smith, 1996); and (3) National Centre for Environmental Prediction (NCEP)-Department of Energy Reanalysis-2 (NCEP-R2) products (Kanamitsu et al., 2002). Brief descriptions of these datasets and basic data analysis are provided below.

1. TRMM 3B42 version-6. TRMM and other satellites precipitation product includes three-hourly precipitation rates based on multi satellite data analysis with original grid cells of $0.25^{\circ} \times 0.25^{\circ}$ extending from $50^{\circ} \mathrm{N}$ to $50^{\circ} \mathrm{S}$ (Huffman et al., 2007). TRMM 3B42 is widely considered to be one of the most reliable high-resolution precipitation datasets over the tropics, although the sub-daily timescale still contains uncertainties over the ocean ( $\mathrm{Li}$ and $\mathrm{Fu}, 2005)$. Nonetheless, Huffman et al. (2007) showed that a diurnal cycle of TRMM product aligns well with gauge observations by showing only slight differences in phase and amplitude. We used version-6 data extending from 1 January 1998 to 31 December 2009. To match the spatiotemporal resolutions to the other observational datasets used here, the TRMM data were spatially regridded using an inverse-distance-weighting remapping technique from a fine resolution to a coarser resolution $\left(0.25^{\circ} \times 0.25^{\circ}\right.$ to $1.0^{\circ} \times 1.0^{\circ}$ and $\left.2.5^{\circ} \times 2.5^{\circ}\right)$ and from three-hourly to daily in time. To impede any contamination of ER wave signals to the spectrum over the Kelvin wave band, the meridional ranges were bounded between $20^{\circ} \mathrm{S}$ and $20^{\circ} \mathrm{N}$ (Straub and Kiladis, 2003).

2. NOAA OLR. Daily interpolated OLR datasets from 1 January 1998 to 31 December 2009 obtained from NOAA/NESDIS were used as a proxy to distinguish areas of deep tropical convection. These datasets were observed using an advanced very high-resolution radiometer (AVHRR) sensor on a NOAA polar-orbiting satellite. Resulting data from each scanning swath of the satellite track were stored on a $2.5^{\circ}$ grid, allowing for representation of high wavenumber features. Gaps had been filled with temporal and spatial interpolation by the data provider (Liebmann and Smith, 1996).

3. NCEP Reanalysis-2. Zonal wind $(u)$, meridional wind $(v)$, and geopotential heights $(\Phi)$ obtained from NCEP R-2 were used to substantiate the results. These data are currently available from the present back to 1 January 1979 and supplied by the NCEP-Department of Energy (Kanamitsu et al., 2002). The reason of selecting dynamical datasets from NCEP R-2 was the fact that some errors and biases have already successfully minimized by improving the convective parameterization scheme (i.e. minor tuning on the simplified Arakawa-Schurbet scheme). NCEP R-2 showed a large improvement in its ability to capture the observed variability of CCEWs signals, as compared with NCEP R-1 (Kim and Alexander, 2013; Kim et al., 2013).
However, it should be noted that a possible bias in the dynamical structure of TD-type waves at higher wavenumbers may occur, since almost all the reanalyses (including NCEP-R2) has a significant deficiencies in representing the variability in high-frequency range (Kim and Alexander, 2013). The velocity potential ( $\chi$ ) and stream functions $(\psi)$ calculated from horizontal wind products were also used to emphasize the modulated structures and wave evolution in the lagged composite analysis.

\subsection{Frequency-wavenumber and variance analysis}

The frequency-wavenumber analysis as fundamentally described in WK99 has been employed on the TRMM satellite-based precipitation estimates to diagnose dominant properties and distribution of azimuthal field motions associated with zonally propagating waves. To isolate how certain fields are modulated by the four prominent waves, the linear trend and the first three harmonics of the annual cycle were subtracted from each grid point. For each analysis segment, a time period of 96 days was chosen with 65-day step, resulting in a total of 139 overlapping sets of time series data ( $\sim 12$ years). In order to minimize the effect of spectral leakage in the Fourier transform, the anomalies of filtered fields for each segment were tapered using a split-cosine-bell function. The power spectra were calculated and averaged for successive overlapping segments, and integrated along meridian over $20^{\circ} \mathrm{N}-20^{\circ} \mathrm{S}$. Since the power spectrum peaks were largely concealed by the red background spectrum, the statistical stability of spectral peaks was obtained by dividing the raw spectra by the noise background smoothed 40 times in wavenumber and frequency with a 1-2-1 filter. Additionally, to prevent loss of data at the beginning and end of the filtered series, both edges of each anomaly segment were padded with 659 days of zeroes following the real-time monitoring technique as discussed by Wheeler and Weickmann (2001).

As the disturbances tend to propagate asymmetrically along the latitude of the Intertropical Convergence Zone (ITCZ), a modified space-time filter as in Straub and Kiladis (2002) has been applied to the raw datasets without partitioning into equatorial symmetric and anti-symmetric components (no symmetry constraints). To illustrate the process of filter selection, Figure 1 displays the observed spectra in their original form about the equatorial band from $20^{\circ} \mathrm{S}$ to $20^{\circ} \mathrm{N}$. The heavy solid polygons denote the spectral filter boundaries, which enclose pronounced spectral peaks in the areas corresponding to the shallow water theory dispersion curves for Kelvin, $n=1 \mathrm{ER}, \mathrm{MRG}$ and TD-type waves. A low frequency cut-off of 17 days was used for the Kelvin wave spectral domain in order to separate it from the MJO band. As for TD-type waves, a high-frequency cut-off of 2.5 days was used to avoid spectral mixtures with westward inertio-gravity waves. The frequency cut-offs for $n=1$ ER and MRG waves were similar to that used by WK99 and Kiladis et al., 2009 , respectively. Equivalent depths $(H)$ associated with equatorial wave modes were set ranging from 8 to $90 \mathrm{~m}$, 


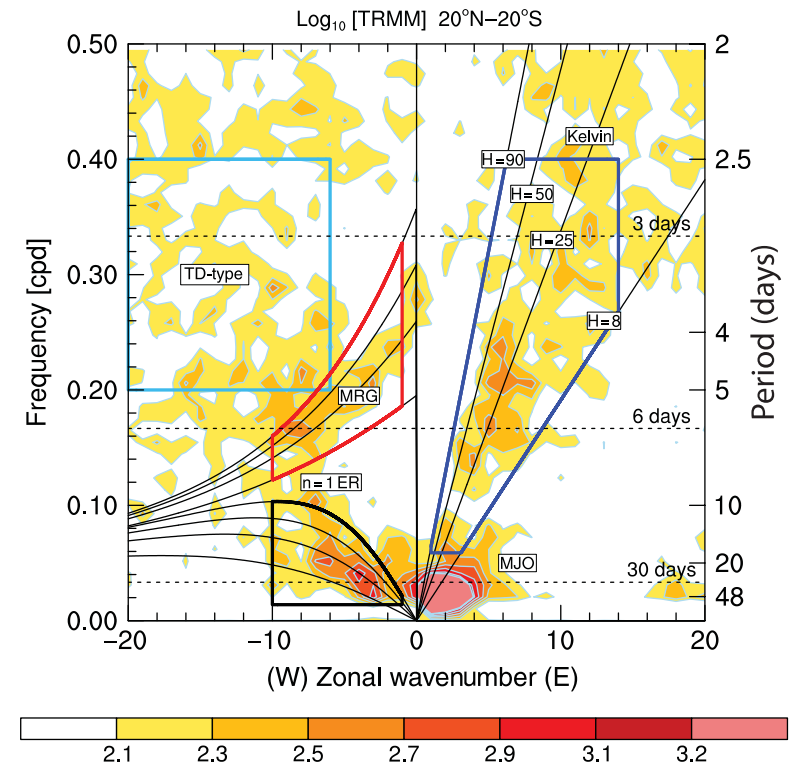

Figure 1. Wavenumber-frequency spectra of TRMM daily precipitation from 1998 to 2009 between $20^{\circ} \mathrm{S}$ and $20^{\circ} \mathrm{N}$ without symmetric partition. The heavy solid polygons indicate domains for the filtering the Kelvin, $n=1 \mathrm{ER}, \mathrm{MRG}$, and TD-type waves. The thin solid lines indicate the

dispersion curve for the equivalent depths of $8,25,50$, and $90 \mathrm{~m}$.

except TD-type waves which do not correspond to any linear equatorial wave theory. Such filter was also applied for a particular season (DJF, MAM, JJA, and SON) to assess the modulation of seasonal precipitation attributed to CCEW activity (Figures S1-S4).

Variance analysis reveals the geographical distribution of the locally most active wave amplitude variations. The method was employed similar to Schreck et al. (2013), which estimates the fraction of total variance contributed by a filter wave band at a given point. The 12-year mean, linear trend and the first three harmonics of the seasonal cycle were removed from the original data. In order to obtain a quantity that represents the fraction of the total variance, the resulting anomalies were normalized by their daily standard deviations $(\sigma)$ at each grid point. These standardized anomalies were then filtered with specified wavenumbers, frequencies, and a pair of equivalent depths in accordance to the filtering domains as defined earlier. Therefore, it must be interpreted carefully that these values are the fraction of the total variance which falls within a given filter band, rather than presuming that they are the fraction of the total variance associated with a given wave. Furthermore, the seasonal variations are calculated as the long-term mean monthly wave activity from 1998 to 2009 , and averaged along meridians over $20^{\circ} \mathrm{N}-20^{\circ} \mathrm{S}$.

\subsection{Lagged regression composites}

The time-lagged composite analysis characterizes the evolution of convective and dynamical perturbation signals over time. The method was adopted from Wheeler et al. (2000) and Kiladis et al. (2009) with slight modifications. Time series of the filtered precipitation rates were obtained at specified single grid points (hereafter called as base

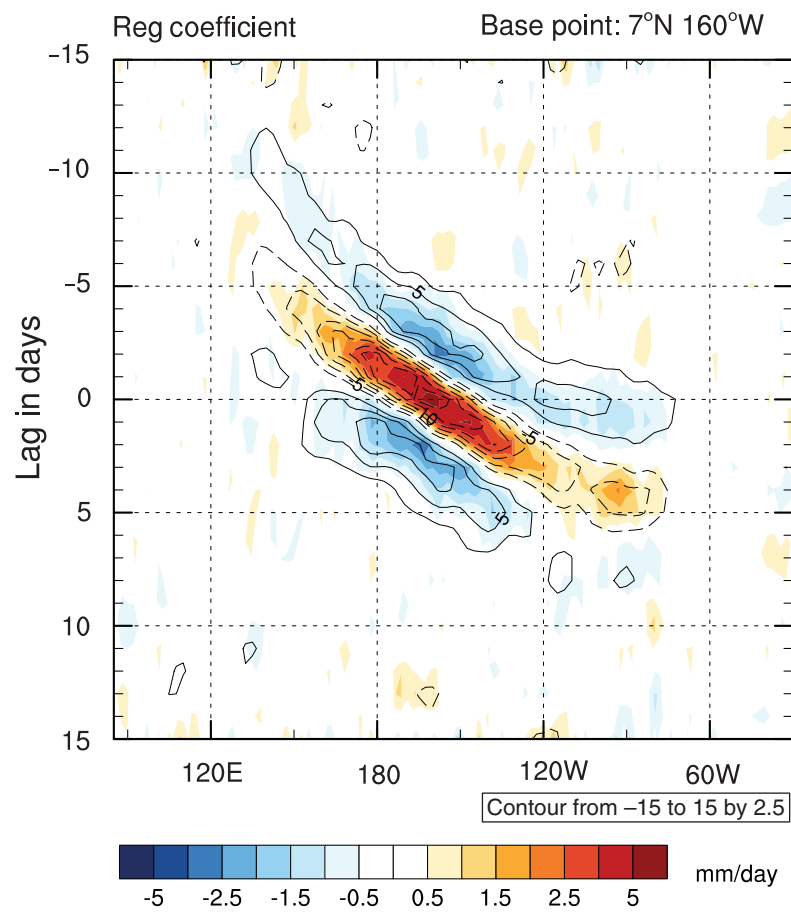

Figure 2. Regressed space-time evolution of precipitation associated with convectively coupled Kelvin waves. Results are based on lagged linear regressions of raw precipitation data onto Kelvin-wave-filtered data at base point $7^{\circ} \mathrm{N}, 160^{\circ} \mathrm{W}$. Shading (hatching) denotes positive (negative) regression coefficients of precipitation in unit of $\mathrm{mm} \mathrm{day}^{-1}$. The solid (dashed) contours denote the suppressed and enhanced OLR anomalies in unit of $\mathrm{W} \mathrm{m}^{-2}$. This composite is calculated using entire period of TRMM available regardless of season. Results are only shown for a significance level $\geq 95 \%$.

points). The respective base point was selected as the one with maximum variance of filtered precipitation during the 12-year TRMM observational period. The windowed variances were used as a threshold to maximize the signal-to-noise ratio following Wheeler et al. (2000). In other words, only discrete signals which have windowed variances exceeding the total mean variance (i.e. strong wave activity) were considered for the composites. The windowed variance length was equal to the period of the lowest frequency for each wave, namely 17 days for the Kelvin waves, 72 days for the $n=1$ ER waves, 10 days for the MRG waves, and 10 days for TD-type waves. Nonetheless, the results were relatively insensitive to modifications of these choices. The resulting filtered precipitation anomalies in a new reconstructed time array were then linearly regressed onto respective raw datasets and rescaled using the standard deviation from the base point of the observations.

The statistical significance of the composite anomalies was calculated by a local two-sided significance test. For calculating the effective number of independent samples (or degrees of freedom) in the $t$-test, we take the autocorrelation into account following Zwiers and von Storch (1995). Results were only shown for a significance level $\geq 95 \%(\alpha \leq 0.05)$. The incomplete beta function in order to estimate two-tailed probability of a random variable was calculated after Press et al. (1986). Positive/negative 
(a) Lag: -2 days

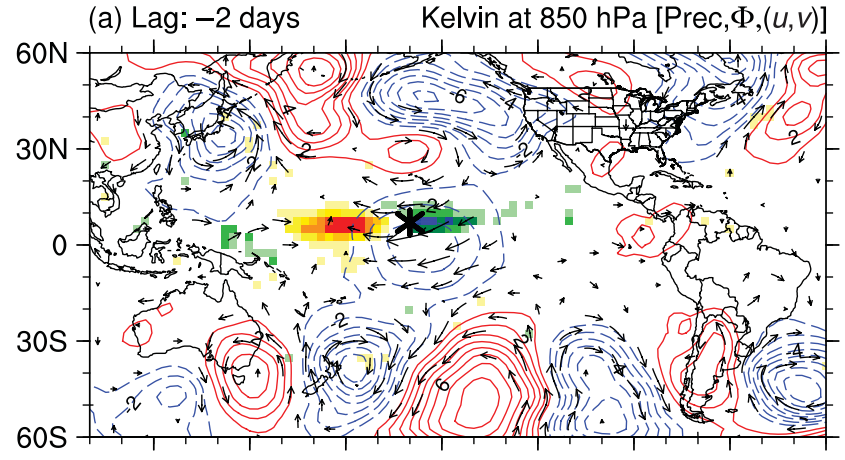

(b) Lag: -1 days

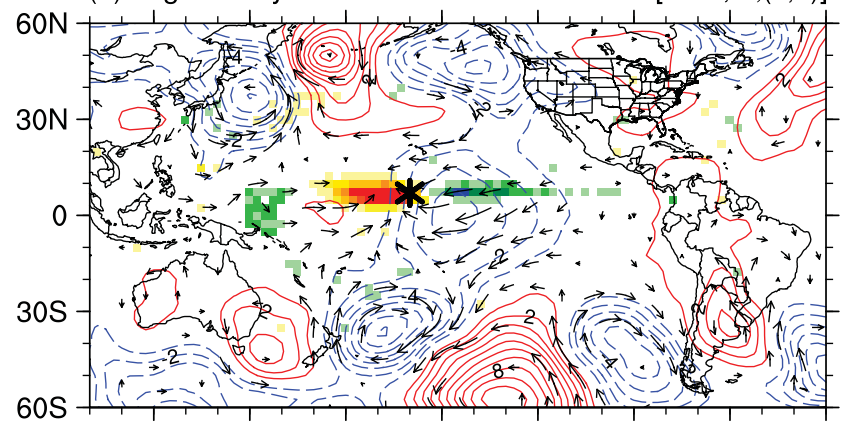

(c) Lag: 0 days

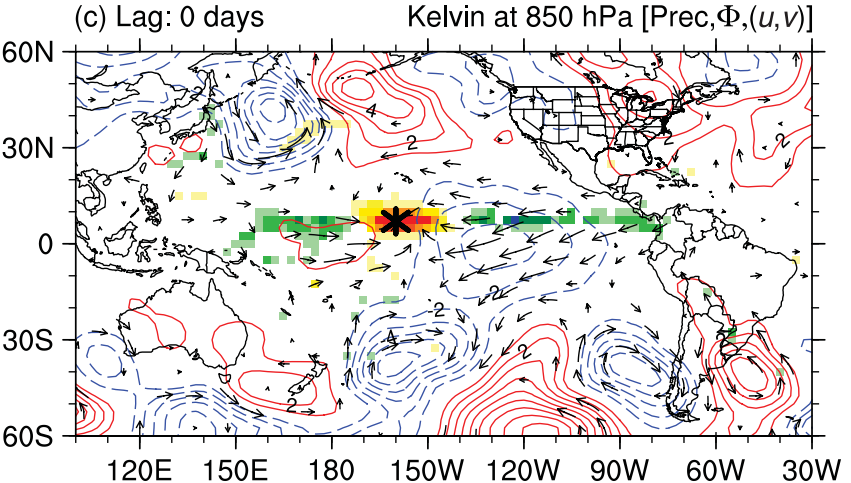

(d) Lag: 1 days

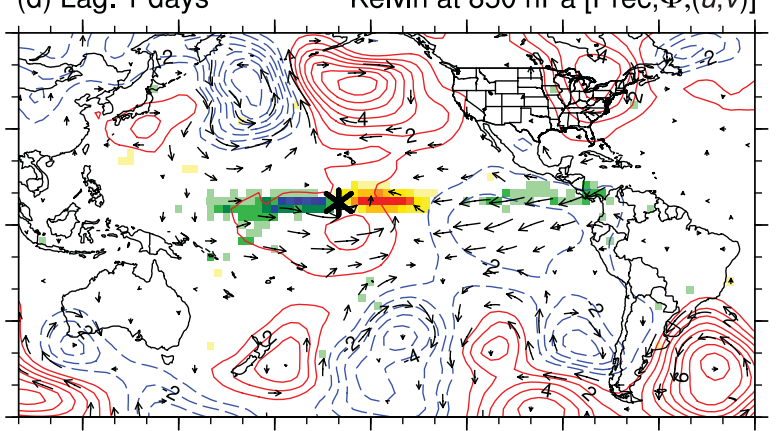

(e) Lag: 2 days

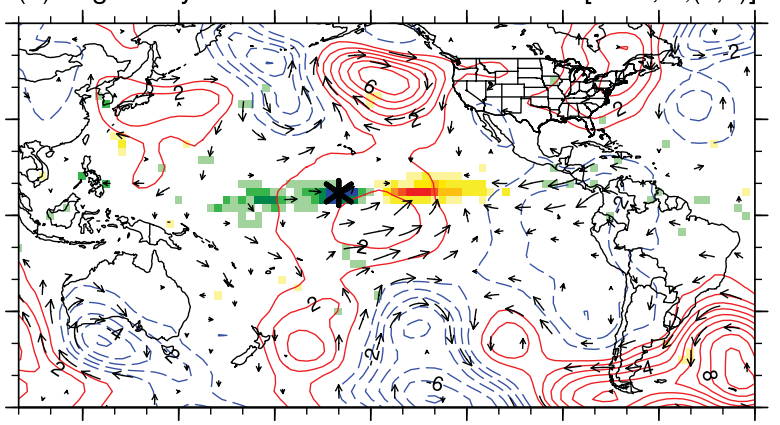

(f) Lag: 3 days

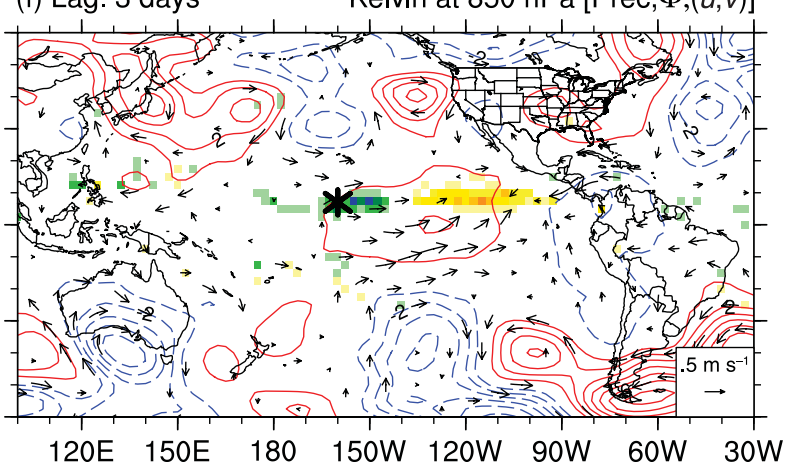

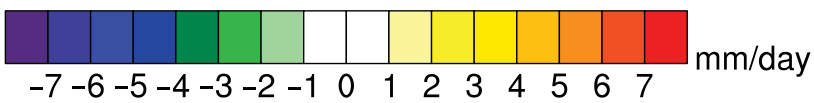

Figure 3. Lagged composite of precipitation (shading), geopotential height (contours), and wind (vectors) associated with Kelvin-wave-filtered time series of precipitation at the base point $7^{\circ} \mathrm{N}, 160^{\circ} \mathrm{W}$ for (a) day -2 , (b) day -1 , (c) day 0 , (d) day 1 , (e) day 2 , and (f) day 3 at $850 \mathrm{hPa}$. Contours are drawn every $1 \mathrm{~m}$ with negative (positive) contours in black (grey) and the zero contours omitted (the values are shown in Blue and Red in the online version). Scales for each figure are based on the standard deviation of the based point Kelvin-filtered time series. All fields are locally significant at the $95 \%$ confidence level; with the largest vectors are around $1.5 \mathrm{~m} \mathrm{~s}^{-1}$. This composite is calculated using entire period of TRMM available regardless of season

lags in the regression coefficient refer to relative periods after/before the peak of precipitation (convection) at the base point on day 0 .

\section{Dynamics of modulated structures}

\subsection{Kelvin wave}

Figure 2 shows the time-longitude regression composite of raw precipitation and OLR anomalies onto Kelvin-wave-filtered data at a base point at $7^{\circ} \mathrm{N}, 160^{\circ} \mathrm{W}$. The regression coefficients have been averaged along meridian of $5^{\circ}$ width relative to the base point. Stronger convective signals associated with enhanced precipitation and suppressed OLR are clearly visible in phase, and they propagate eastward with an approximate velocity of $15.4 \mathrm{~m} \mathrm{~s}^{-1}$. This characteristic conveys a typical speed and evolution of Kelvin wave activity over the Pacific. The waves are evident in the vicinity of the Maritime Continent on day -7 and travel to the east into the eastern Pacific Ocean on day +7 .

Figure 3(a)-(f) illustrates the composite Kelvin wave-filtered precipitation in the lower troposphere at $850 \mathrm{hPa}$, and only associated fields that are statistically significant at $95 \%$ level are shown. The entire composite pattern propagates eastward indicated by an 
eastward moving precipitation pair locus from the western Pacific Ocean towards the eastern Pacific Ocean and the Caribbean Sea. The dynamic structure of the wave remains mostly constant, with nearly symmetrical shapes about the equator, and resembles the theoretical structure of Kelvin waves based on theories of frictionally modified Kelvin waves (cf Salby et al., 1994; Masunaga, 2009). The dominant wind anomalies are easterlies and westerlies diverging out of the moist anomaly. The latitudinal symmetry of geopotential height anomalies is in phase with predominant zonal wind anomalies, while the contribution of the meridional flow tends to vanish around the strong convective locus. Intriguingly, the resulting precipitation fields from the composites appear to be slightly asymmetric, with the greatest amplitude centralized in the Northern Hemisphere. These patterns are comparable to the brightness temperature (Tb) composites by Kiladis et al. (2009), who also pointed out that this asymmetry-modulated structure occurs because of particularly low sea surface temperatures (SSTs) in the eastern Pacific, in turn causing a unique convection mechanism over this region. Precipitation anomalies induced in the predominant east-west wind directions of the Kelvin wave structure imply that wave-convection interaction has a considerable contribution in organizing the characteristics of local precipitation (Holder et al., 2008).

The tropical-extratropical interaction within the Kelvin wave signals in the lower troposphere at $850 \mathrm{hPa}$ is also analysed in Figure 3(a)-(f). The poleward flow from the Kelvin wave structure, which is likely a part of the eastward-propagating Rossby wave train response to convective heating in tropics is evident, as found by Straub and Kiladis (2002). This poleward flow is strongly linked with the Kelvin wave troughs and plays a substantial role in transporting equatorial humid air towards the off-equatorial region ( $c f$ Masunaga, 2009). On the other hand, equatorward flows that emanate from extratropical Rossby wave trains have been shown to contribute to positive moisture anomalies in equatorial Kelvin wave structure (Figure 3(e)-(f)). Composites for each specific season (Figures S5-S8) reveal that such extratropical forcing on Kelvin waves structure are predominant during boreal summer (JJA) over the eastern Pacific, and become relatively weak or diminished during boreal winter-spring. The fact that Kelvin wave events in the Pacific are often dynamically forced by eastward propagation of subtropical Rossby waves excited in the Southern Hemisphere subtropical jet (as shown in Figure 3(a)-(f)), suggests that phasing of southern extratropical Rossby waves within Kelvin wave structures plays a substantial role in controlling the quantity and pattern of modulated precipitation over this region, especially during boreal spring and summer.

Figure 4(a)-(f) shows the composite Kelvin wave-filtered precipitation in the upper troposphere at $200 \mathrm{hPa}$. This upper-level composite is broadly dominated by a Rossby wave activity propagating into the eastern tropical Pacific from the mid-latitudes. Such feature is strongly observed during boreal winter-spring since the northern basic state facilitates more the equatorward propagation of extratropical waves; and it becomes relatively less pronounced during boreal summer-fall (Figures S9-S12). This intertwined pattern of Kelvin and extratropical Rossby waves appears as a result of contaminating filter bands by eastward moving deep convection and upper cloud signals forced by the extratropical Rossby waves, particularly during boreal winter-spring (cf Kiladis, 1998; Schreck et al., 2013). The moist and dry anomalies have a southwest-northeast tilt over the structure of the northern extratropical Rossby-wave train, which is consistent with previous findings of $200-\mathrm{hPa}$ UTWV composites from the high-resolution infrared radiation sounder (HIRS) by Schreck et al. (2013). The positive anomalies are induced in the upper tropospheric cyclonic vortex and coincide with $200-\mathrm{hPa}$ southwesterlies. The horizontal advection of southwesterly flow of the subtropical wave train gives the positive moisture anomalies in the subtropics, and the northeasterly of the subtropical flow contributes to negative moisture anomalies to the tropics. It must be noted that as the filter was designed based on the dispersion curves of shallow water theory in a resting background state, one cannot avoid some of these projections contaminating the Kelvin-filter band. However, such contamination is less evident during boreal summer-fall, as extratropical Rossby waves are less forced to guide eastward-moving deep convection towards the equatorial eastern Pacific.

\subsection{The $n=1 \mathrm{ER}$ wave}

The base point used for composite regression of the convectively coupled ER wave-filtered precipitation is chosen at $7.5^{\circ} \mathrm{N}, 172.5^{\circ} \mathrm{E}$, as shown in Figure 5. The OLR regression coefficients are overlaid to shed light on phase relationship between the two fields. As expected from the dispersion curve of shallow-water ER waves, the regressed fields show pronounced westward phase propagation and slowly eastward group velocity. The implied phase and group velocities are -4.8 and $0.7 \mathrm{~m} \mathrm{~s}^{-1}$, respectively. Typical evolution of the ER wave precipitation begins on day -12 , about $42^{\circ}$ west of the reference point, and develops up to the eastern Pacific on day +14 , for around 26 days.

The lagged composites in Figure 6 illustrate that the general structures of convectively coupled ER waves in modulating precipitation are formed as predicted by equatorially trapped shallow-water structures. The convective signal indicated by positive precipitation anomalies is displaced to the east of the cyclonic gyres. It is also collocated with symmetries of geopotential height near the equator, and predominant easterly wind perturbation at the east of the convective centre. Following the development of this wave at earlier lags (day -18 to day -10 , not shown), one may see that the region of enhanced convection first appears 5-6 days earlier in the eastern Pacific (around $90^{\circ} \mathrm{W}$ ). By day -12 , the precipitation is induced and the associated cyclone pair structure starts to reflect the ER-related gyres at day -10 . After 2 days, the symmetric geopotential height wave begins to develop and emphasizes the 
(a) Lag: -2 days

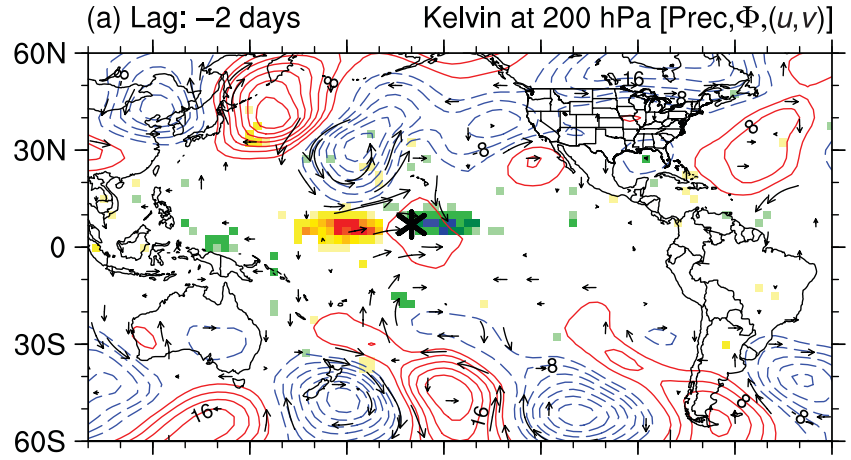

(b) Lag: -1 days

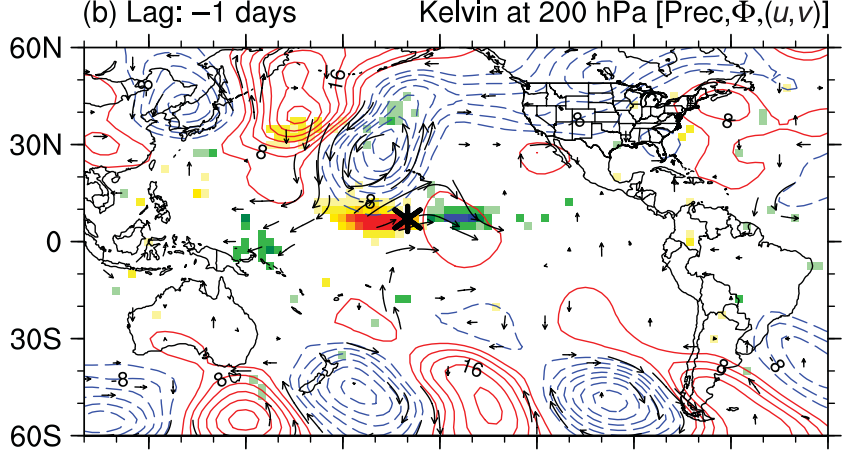

(c) Lag: 0 days

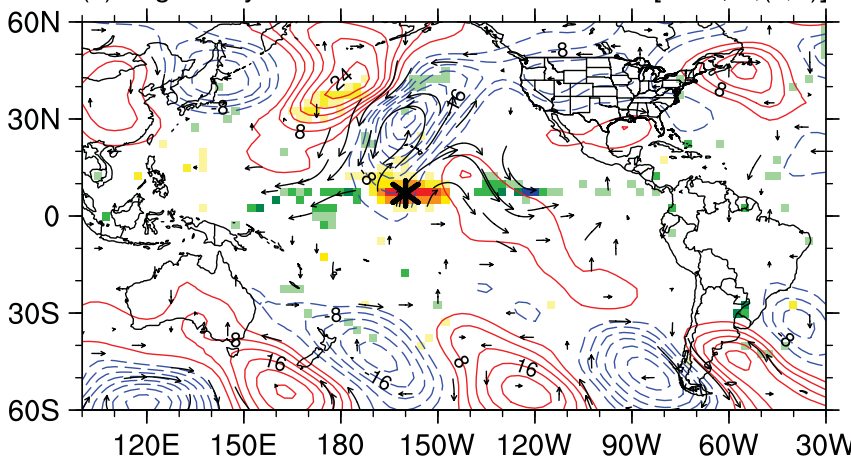

(d) Lag: 1 days

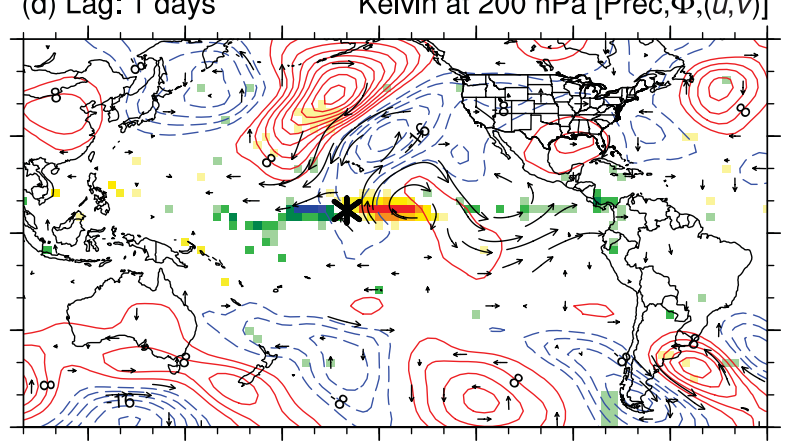

(e) Lag: 2 days
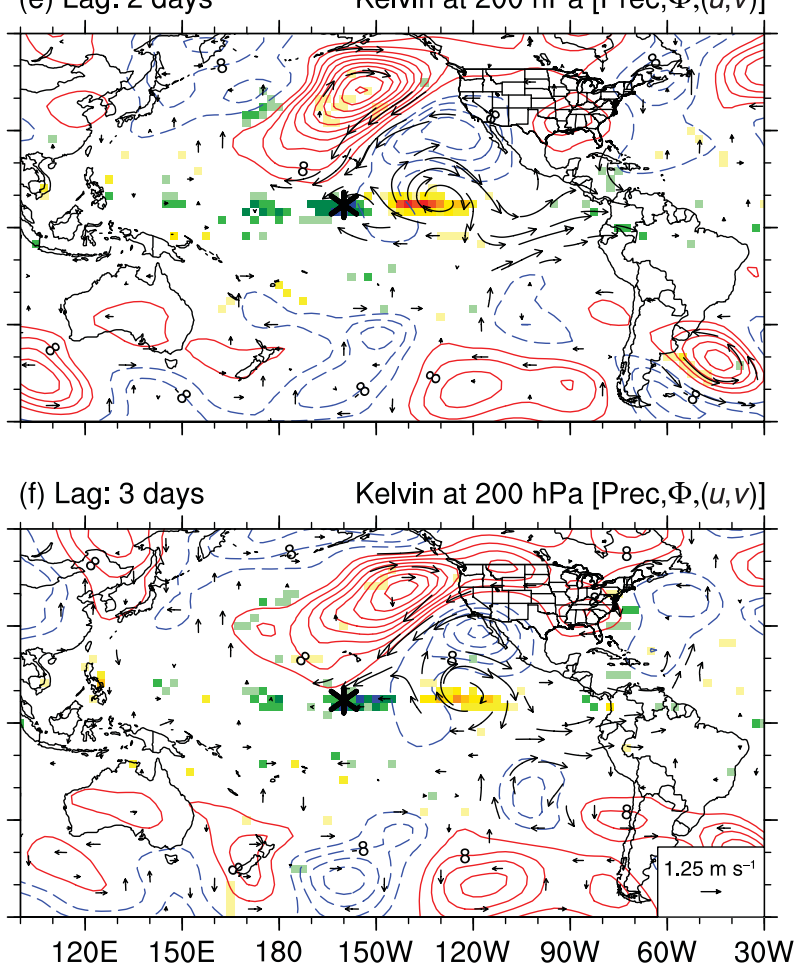

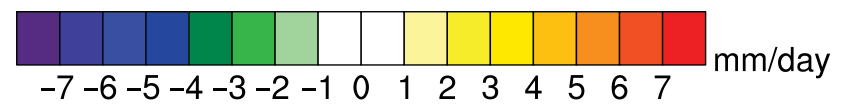

Figure 4. Similar to Figure 3, but for the upper-level troposphere at $200 \mathrm{hPa}$. All fields are locally significant at the $95 \%$ confidence level; with the largest vectors are around $3.0 \mathrm{~m} \mathrm{~s}^{-1}$.

robust structure of ER wave at the following lag on day -8 (Figure 6(a)). This unique evidence suggests that the pre-existing convection before the wave formation has a vital role in generating ER wave over this region.

Another intriguing feature induced by ER waves is shown on days +8 to +10 (Figure 6(f) and $(\mathrm{g})$ ). Once this wave reaches the region of New Guinea, the northern gyre and convective centre shift to around $10^{\circ} \mathrm{N}$ as they propagate westward, until reaching the South China Sea on day +16 (Figure 6(h)). Such unique modulation may imply that precipitation variability over northern Australia is less affected by their activity compared to Southeast Asia, as with convective modulation structure found by Kiladis et al. (2009). This result is qualitatively not dependent on the choice of base point. Similar patterns were also found when we constructed the composite using another base point of the maximum ER wave variance over the Pacific. It is also worthwhile to hypothesize that the predominant easterly wind perturbation to the east of the convection centre and locally low pressures in equator in early-lag structures (Figure 6(a)-(d)) can be attributed to the forced Kelvin wave response to equatorial heating, as suggested by Gill (1980). This evidence may suggest a possible trigger mechanism for ER waves over this region, which is generated from the Kelvin waves forced by the equatorial heating system ( $c f$ Kiladis et al., 2009). Consistent with previous studies (e.g. Kiladis and Wheeler, 1995; Meehl et al., 1996; Kiladis, 1998), the reversed structures of cyclonic flows and visible interaction to extratropical Rossby wave trains are apparent in the upper troposphere composites at $200 \mathrm{hPa}$ (not shown). Additionally, in order to show whether this pattern is persistent throughout the 


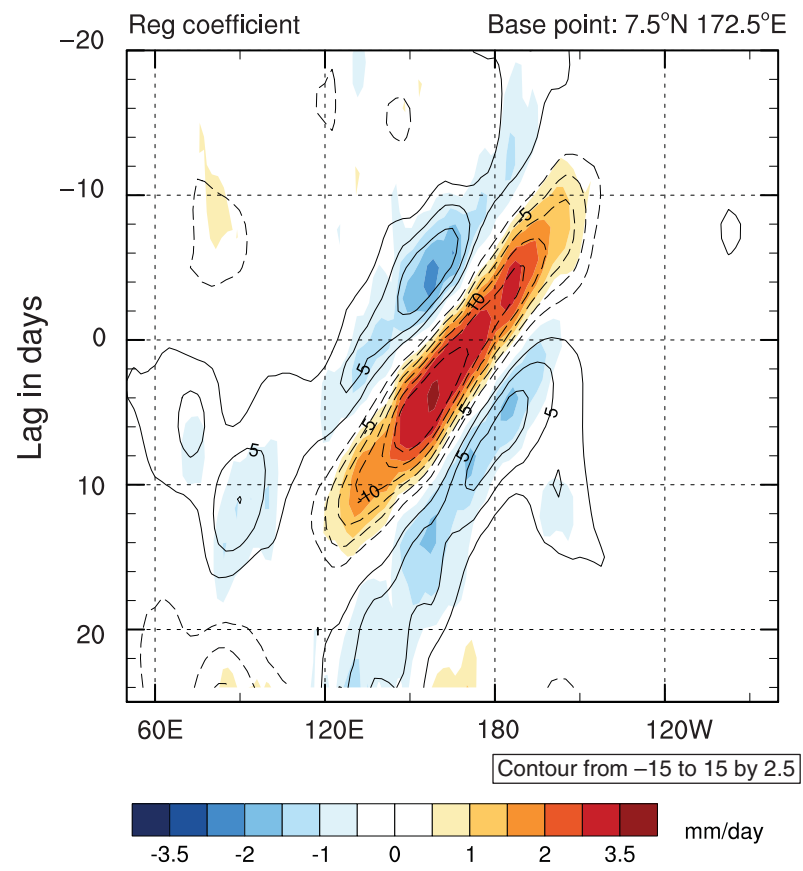

Figure 5. Similar to Figure 2, but for the regressed space-time evolution of precipitation associated with the $n=1 \mathrm{ER}$ waves at the base point $7.5^{\circ} \mathrm{N}, 172.5^{\circ} \mathrm{E}$.

year, we performed a similar analysis by splitting up the period by individual season instead of using the entire calendar year. We found that such features are diminished during boreal summer, and steadily grow in boreal fall to spring (Figures S13-S16). The maximum activity predominantly occurs during boreal winter, with structures similar as those found by Kiladis and Wheeler (1995), and it is consistent with our variance analysis discussed in Section 4.2. In light of the composites, we may deduce that precipitation disturbances associated with convectively coupled ER waves are sometimes induced in phase with enhanced convection in the off-equatorial region, and collocated in the vicinity of convergence of the symmetric cyclone pair structures.

\subsection{The MRG wave}

The MRG-wave-filtered precipitation composite in Figure 7 shows fast westward phase propagation and slow eastward group propagation. The implied phase speed is approximately $-16.1 \mathrm{~m} \mathrm{~s}^{-1}$, coinciding with an eastward energy propagation of approximately $4.5 \mathrm{~m} \mathrm{~s}^{-1}$ at the base point of $7.5^{\circ} \mathrm{N}, 172.5^{\circ} \mathrm{E}$. The signal is robust as seen in the OLR regression which also shows a similar characteristic at $95 \%$ significant level. This lagged-composite result is nearly identical to that of Wheeler et al. (2000), where they are preferentially initiated over the eastern Pacific Ocean and travelling westward until vanishing over the western Pacific with a short life cycle of 4-6 days.

Figure 8 shows a horizontal cross-section of the convectively coupled MRG waves at the 850 -hPa level with a similar base point. The precipitation-filtered composite resembles MRG wave structure from previous studies (Yang et al., 2007; Kiladis et al., 2009). The associated circulation pattern matches well with the theoretical shallow water structure; the prominently symmetric gyres are centred about the equator, and the convective signal indicated by strong precipitation disturbances coincides with the anti-symmetric velocity potential $(\chi)$. The regions coloured in grey (black) contours correspond to regions in which precipitation tends to be enhanced (suppressed). In addition, the convective signal is always co-located with divergent and convergent meridional flow. The positive (negative) precipitation anomalies corresponding to the enhanced (suppressed) convection are induced anti-symmetrically in regard to the variation of velocity potential, and are jointly followed by the symmetric gyres. The estimated zonal wavelength from this structure is approximately $8340 \mathrm{~km}$ and corresponds to the zonal wave number $(s) \sim 5$.

On closer inspection, at day -2 to -1 the associated circulation structures of MRG waves clearly show a fast westward phase progression (Figure 8(a) and (b)). The counter-clockwise gyres around the equator propagate towards the west, but at this stage they are also followed by the emergence of new anti-cyclonic gyres in the vicinity of the eastern Pacific on day -1 . On day 0 , the strong precipitation that previously appeared in the eastern Pacific on day -2 is now located precisely over the base point (Figure 8(c)). The anti-cyclonic gyres are intensified, and the enhanced (suppressed) convection is most pronounced in the equatorward (poleward) flow. On day +3 (Figure 8(f)), a new birth of anti-cyclonic gyres appears and starts a new cycle. Therefore, it takes approximately 4-6 days to complete a whole cycle, as shown in Figure 7. At the $200 \mathrm{hPa}$ (not shown), the wind field perturbations are reversed. Increased circulation strength and a southwest to northeast tilt of the geopotential and precipitation in the Northern Hemisphere, opposite in the Southern Hemisphere, are visible, as noted by Wheeler et al. (2000). However, the gyres are slightly shifted to the north of the equator, which may suggest that the distortion of upper-level MRG wave structure can be attributed to the response of a heating displacement away from the equator. These overall features are a common case of MRG wave-filtered precipitation observed during boreal summer-fall as they are often forced as part of the eastward-dispersion of energy from low latitude TCs over the western Pacific. On the contrary, such features are diminished during boreal winter-spring along with weakening wave forcings during these seasons (Figures S17-S20).

\subsection{The TD-type wave}

Composites of TD-type wave-filtered precipitation in a lagged-time-longitude diagram, showing typical evolution over the western Pacific Ocean at the base point $7.5^{\circ} \mathrm{N}$, $133^{\circ} \mathrm{E}$, are presented in Figure 9. The phase progression of precipitation associated with TD-type waves indicated by the movement of enhanced or suppressed convective signals is approximately $-9.5 \mathrm{~m} \mathrm{~s}^{-1}$. The waves initiate over the central Pacific near the date line and propagate 

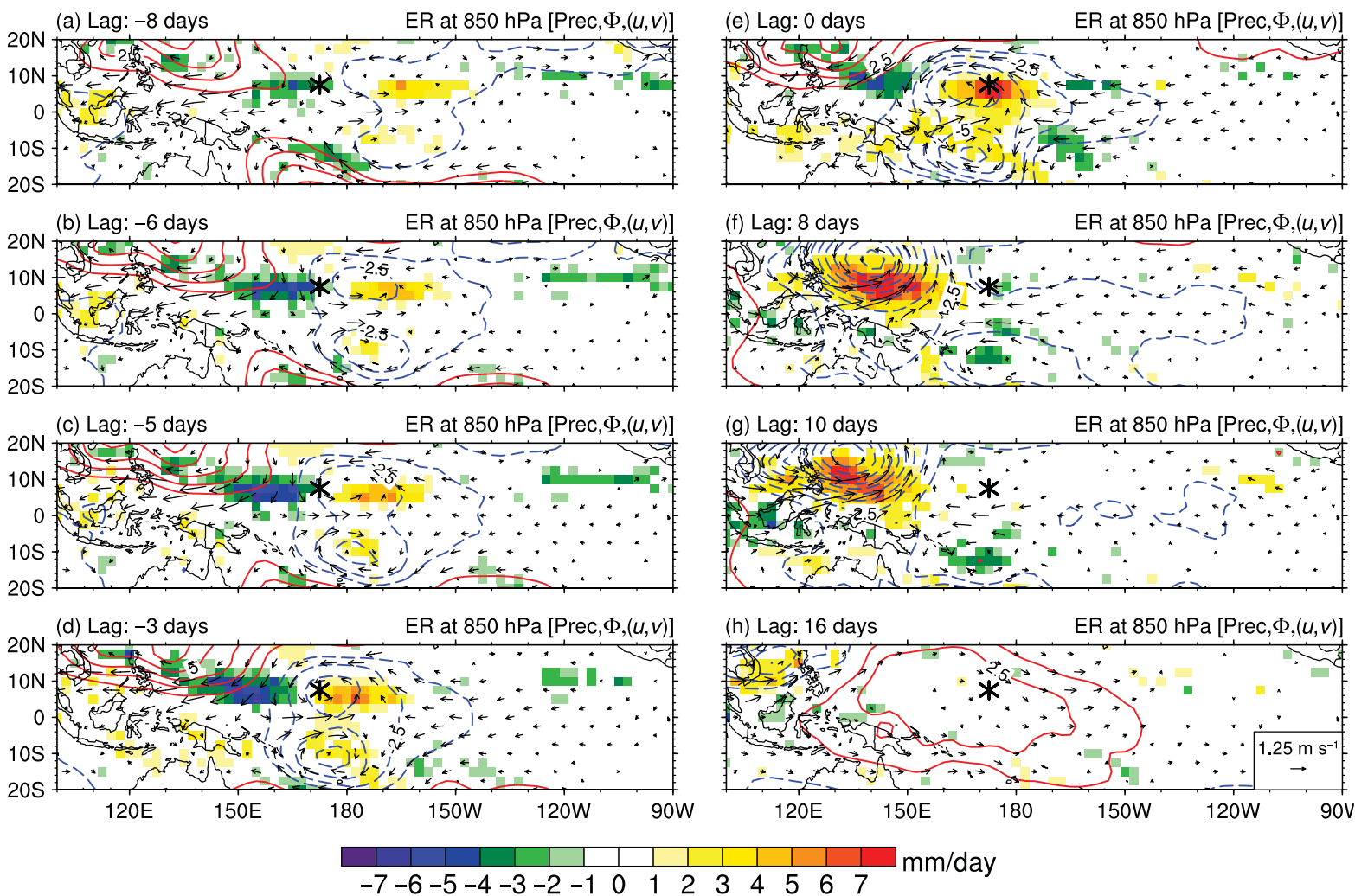

Figure 6. Similar to Figure 3, but for the regressed space-time evolution of precipitation associated with the $\mathrm{n}=1 \mathrm{ER}$ waves at the base point $7.5^{\circ} \mathrm{N}$, $172.5^{\circ} \mathrm{E}$ for (a) day -16 , (b) day -8 , (c) day -5 , (d) day -3 , (e) day 0 , (f) day 5, (g) day 8, and (h) day 10 at $850 \mathrm{hPa}$. The contour increment for geopotential height is $1.25 \mathrm{~m}$ and the largest vectors are around $2.5 \mathrm{~m} \mathrm{~s}^{-1}$. All fields are locally significant at the $95 \%$ confidence level. This composite is calculated using entire period of TRMM available regardless of season.

up to $110 \mathrm{E}$ in the vicinity of the Maritime Continent. The appearance of a dispersive wave packet with a non-zero group velocity is evident with a group progression of approximately $+3.5 \mathrm{~m} \mathrm{~s}^{-1}$.

Figure 10(a)-(d) represents the evolution of convectively coupled TD-type waves in modulating precipitation at the $850-\mathrm{hPa}$ level. Generally, the circulation is evidenced by vortical flow generated in the western Pacific, moving northwest and vanishing above the South China Sea at 110 E. On day -1 , two gyres appear to perturb over the Philippines, with high precipitation disturbance located over the cyclonic region of enhanced convection. These wave packets modulate precipitation and move westward with propagation tilted towards the northwest. On day 0 , three gyres are pronounced with slightly northwest shifts compared to day -1 . There are positive precipitation anomalies centred over the base point flanked by suppressed convection. The convective signal is co-located with an anomalous cyclone, indicating that convection induces strong precipitation within the trough of the wave. The negative precipitation from suppressed convection to the east and west of a convective signal is associated with an anomalous anticyclone. At the later lags (day +4), similar vortical circulation fields remain and develop with a zonal wavelength of $\sim 2500 \mathrm{~km}$. The composites shown in Figure 10 are a common feature observed during boreal summer-fall when TD-type waves are most active; while during boreal winter-spring, these patterns are relatively diminished as they are relatively less forced (Figures S21-S24). In addition, regression at the mid-tropospheric layer $(600 \mathrm{hPa}$ at day 0$)$ reproduces similar structure as in the lower layer, but in the upper troposphere $(200 \mathrm{hPa}$ at day 0$)$ the associated circulation slightly differs and shows a more pronounced horizontally-tilted pattern when compared to the lower troposphere (not shown). Kiladis et al. (2006) found similar evidence at upper tropospheric TD-type structure over Africa, which showed that such behaviour is associated with a poleward flux of westerly momentum strengthening during boreal summer. However, the mechanism explaining such tilted pattern over the western Pacific has not yet been closely investigated.

In summation, enhanced (suppressed) precipitation anomalies associated with dynamic-structure TD-type waves are primarily emanated at the wave's trough (ridge) of an off-equatorial vortex train, in which the strong (weak) convection induced by vortical flow may favourably occur.

\section{Precipitation variability attributed to CCEW activities}

\subsection{Spatial climatology}

Figure 11(a)-(d) shows the fraction of the total precipitation variance (shading in \%) overlaid with the total 


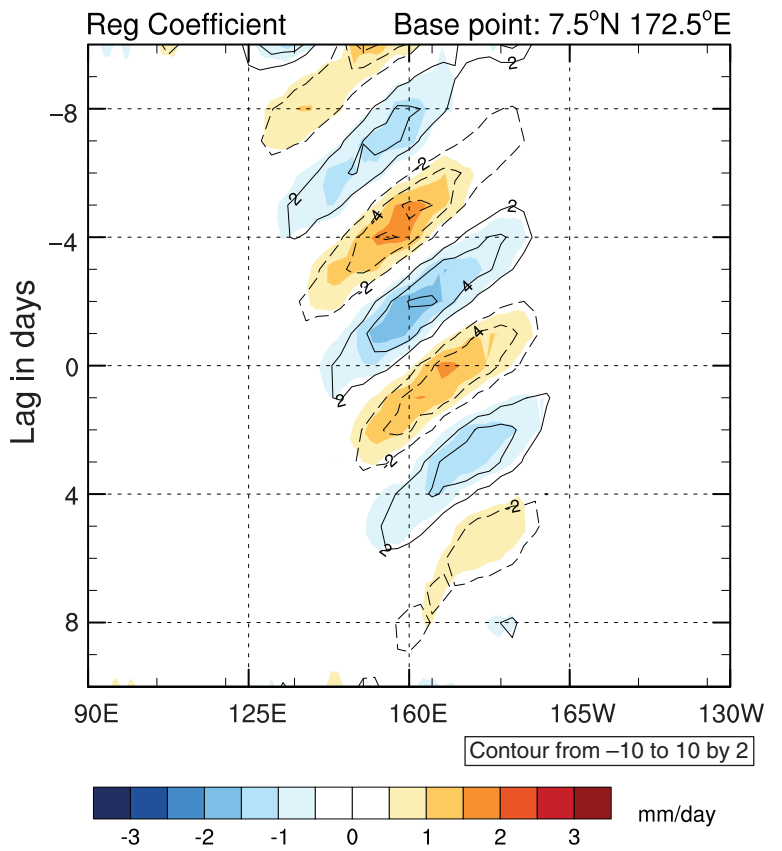

Figure 7. Similar to Figure 2, but for the regressed space-time evolution of precipitation associated with the MRG waves at the base point $7.5^{\circ} \mathrm{N}$, $172.5^{\circ} \mathrm{E}$.

variance (contour in $\mathrm{mm}^{2} \mathrm{day}^{-2}$ ), which falls within the frequency-wavenumber range defined by the filter band of the respective waves. These maps are calculated as described in Section 2.2. and represent the geographic distribution of the locally most active amplitude waves, which experience strong influence from CCEW activities. It should be noted that as the variance has been normalized by each grid point's standard deviation, the values shown here reflect the climatological percentage of precipitation variability supplied by the waves, regardless of the season.

A map of Kelvin-wave-filtered precipitation variance (including both the symmetric and anti-symmetric components of precipitation) is shown in Figure 11(a). Kelvin waves exhibit to control a large portion of precipitation variability throughout the tropics, between $10^{\circ}$ north and south. Generally, the impact of Kelvin waves on precipitation over the tropics is inhomogeneous. A considerable ratio of 6 to $10 \%$ is found to cover most of the tropical ocean, while less than $6 \%$ of the total variance accounts for the precipitation over tropical lands, excluding eastern Brazil and the west coast of Africa. There are at least three regions profoundly dominated by Kelvin wave activity, resulting in approximately $8 \%$ of the total variance, including the Indian Ocean centred at $90^{\circ} \mathrm{E}$, the Pacific ITCZ between $5-12^{\circ} \mathrm{N}$, and the stretch of the Atlantic Ocean from South America to Africa between $0-5^{\circ} \mathrm{N}$. The maximum influence over the two latter regions has already been investigated to be due to an effective intrusion of extratropical Rossby wave train activity (Straub and Kiladis, 2003; Masunaga, 2009; Schreck et al., 2013) and sea level pressure surges propagating from extratropical South America into the deep tropics (Liebmann et al., 2009), while the excitation mechanisms over the Indian Ocean and Africa are mainly related to the Mesoscale Convective Systems (MCSs), MJO, and latent heating within the region of the African easterly jet (Masunaga et al., 2006; Leroux and Hall, 2009; Kim and Alexander, 2013).

The variance of the convectively coupled MRG waves (Figure 11(b)) is of a smaller magnitude than that of Kelvin waves and mostly confined to the region near the date line; along the migration path of the ITCZ, from the western to north-eastern Pacific Ocean and Atlantic Ocean, and along the southern Pacific Convergence Zone (SPCZ) over the south-western Pacific Ocean. In these regions they account for more than $3 \%$ of total variance, with their peaks shifted off the equator. As in previous studies (Hendon and Liebmann, 1991; RF04; Huang and Huang, 2011), the maximum influence of MRG waves is shown as twin bands along $8^{\circ}$ latitude in both hemispheres, where the magnitude of variance in the Southern Hemisphere is smaller than in the Northern Hemisphere (2-3.5\% lower in magnitude). Hendon and Liebmann (1991) postulated that the localization of this twin-band wave activity is due to a unique meridional distribution of SST in the eastern Pacific Ocean along the latitude of $7.5^{\circ}$. Such patterns are strongly pronounced during boreal fall around the date line in association with the asymmetric fluctuation of SSTs. As with Kelvin waves, the considerable ratio of modulated precipitation variance over the surrounding ocean is more pronounced than over land. Notable influences over land with ratios of $2-3 \%$ are evident over the Philippines, Sri Lanka, Thailand, Cambodia, Vietnam, Central America, and West Africa. RF04 found a slightly comparable result, that less than a $5 \%$ of total global OLR variance was contributed by this tropical mode.

Figure 11(c) shows distribution of total precipitation variance attributed to the convectively coupled ER waves. The activity of $n=1$ ER waves is centred off the equator, with strong impacts occurring at approximately $12^{\circ}-15^{\circ}$ latitude. These features are consistent with the theoretical shallow water ER waves (Matsuno, 1966; Wheeler et al., 2000), which experience maximum convection off the equator and non-zero convective signal at the equator. Pronounced precipitation variances with percentage ratios of 4-5\% mainly cover most of the Asian monsoon region, warm pools of the north-western Pacific Ocean, and in the vicinity of SPCZ over the south-western Pacific Ocean. Less variance is typically located over land $(<4 \%)$, but evident over Southeast Asia, northern Australia, and Central America.

Figure 11(d) shows the total variance of precipitation variability modulated by TD-type wave activity. It can be seen that the most dominant influences with ratios of $10-15 \%$ are evident over three maximum regions, including the western Pacific, eastern North Pacific, and eastern Atlantic Ocean (stretching from African Coast). These three regions are widely known as the regions most affected by TD-type waves (Kiladis et al., 2006; Mekonnen et al., 2006). The stronger activity of TD-type is situated over the West African Coast, explaining up to $15 \%$ of total precipitation variance. Gu and Zhang (2001), using 

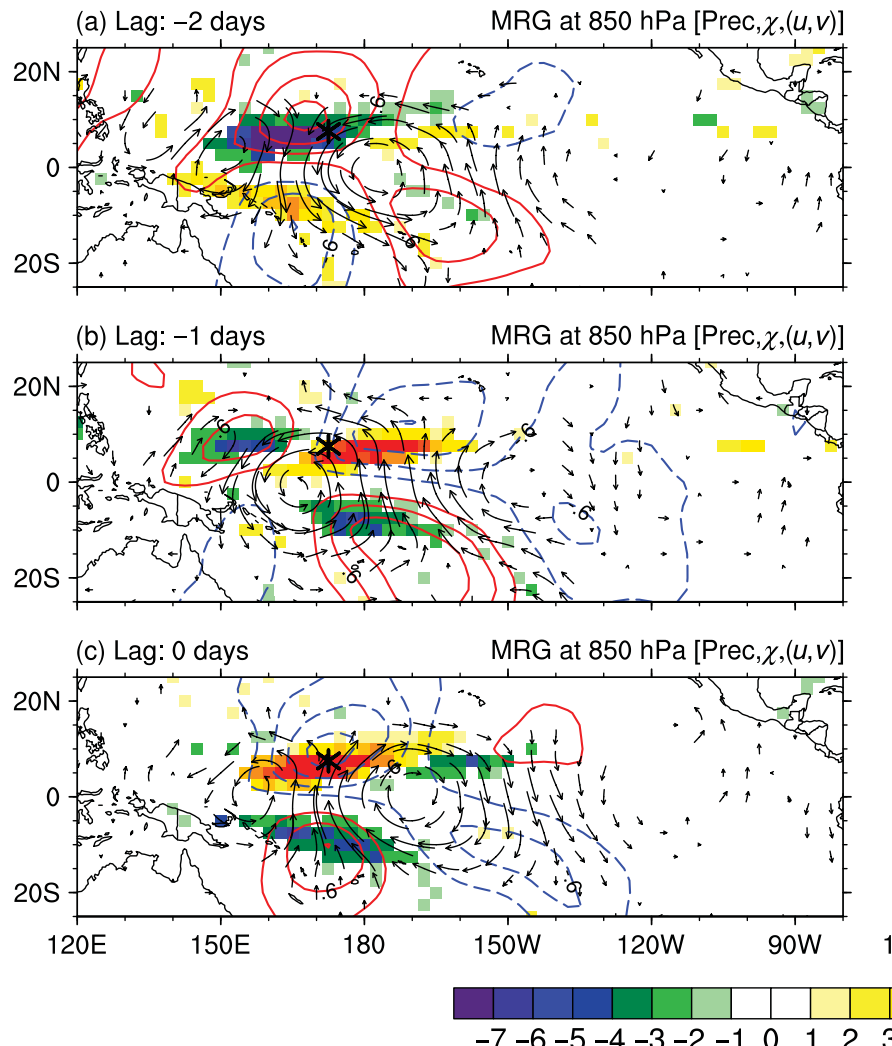

(d) Lag: 1 days
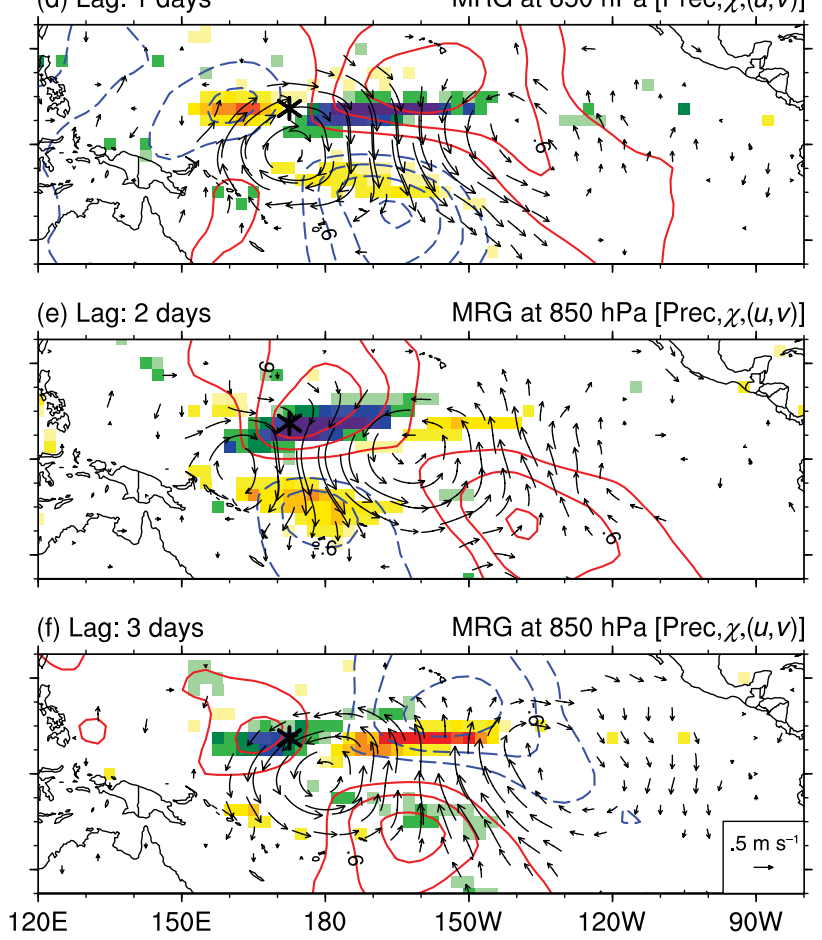

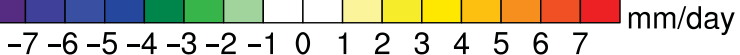

Figure 8. Similar to Figure 3, but for the regressed space-time evolution of precipitation associated with the MRG waves at the base point $7.5^{\circ} \mathrm{N}$, $172.5^{\circ} \mathrm{E}$ for (a) day -2 , (b) day -1 , (c) day 0 , (d) day 1 , (e) day 2 , and (f) day 3 at $850 \mathrm{hPa}$. The contour increment for velocity potential ( $\chi$ ) is $3 \times$ $10^{5} \mathrm{~m}^{2} \mathrm{~s}^{-1}$ and the largest vectors are around $2.0 \mathrm{~m} \mathrm{~s}^{-1}$. All fields are locally significant at the $95 \%$ confidence level. This composite is calculated using entire period of TRMM available regardless of season.

OLR data, found a similar result, namely that TD-type waves contributed up to $15 \%$ of the total convective variance over Africa. The variance of TD-type waves compared to $n=1 \mathrm{ER}, \mathrm{MRG}$, and Kelvin waves is of a larger magnitude, and more ubiquitous over the tropics, particularly over regions that often experience TCs. This suggests that TD-type waves have a greater influence on precipitation than the other three wave types. A closer inspection of Figure 11(d) shows that less than $8 \%$ of the total variability of precipitation over tropical lands can be found over western Australia, Southeast Asia, South Asia, West Africa, Madagascar, and Central America, while the percentage ratios of greater than $12 \%$ are mainly situated over the ocean within the ITCZ.

\subsection{Seasonal variation}

The seasonal variation of CCEWs as a product of area averages of monthly wave activity between $20^{\circ} \mathrm{N}$ and $20^{\circ} \mathrm{S}$ is shown in Figure 13(a)-(d). Overall, the seasonal cycles of the Kelvin, MRG, $n=1 \mathrm{ER}$, and TD-type waves are in good agreement with other convective proxies used in the previous studies (e.g. Tb, PW, OLR, Huang and Huang, 2011; RF04; WK99). The similarity among these proxies indicates that they are equally capable of capturing modulated disturbances from CCEW activity.

The strongest Kelvin wave impact on precipitation occurs during boreal spring, from March to May, with a maximum value of $6.99 \pm 3.30 \%$ (Figure 12(a)). In contrast, activities observed during boreal summer through autumn are found to be relatively modest, with minimum ratios of $4.09 \pm 1.85 \%$ in September. These results are similar in nature to a rough description from RF04 using a PW dataset, which showed that about $5 \%$ of total PW mean variances come from Kelvin wave activity. In addition, $n=1$ ER waves exhibit their most influential impact during late boreal winter, continuing through early boreal spring, from December to April (Figure 12(b)). It appears that the maximum ER wave impact on precipitation is somewhat similar to the one of Kelvin waves, making up approximately $3.64 \pm 1.63 \%$ of the total variance during boreal winter, and about $3.77 \pm 1.79 \%$ during early boreal spring. This is somewhat less than the values given by RF04, who reported that up to $12 \%$ of the total global OLR variance can be explained by $n=1$ ER waves. The discrepancies could be attributed to the different sensitivity of proxies in capturing the variability, and differences of spatial resolution among datasets.

The seasonal cycle of TD-type waves appear to be similar to that of MRG waves with maximum activity occurs during the boreal late summer and early fall (Figure 12(c) and (d)). The impact of MRG waves on precipitation is relatively modest throughout the seasons, while TD-type waves show a profound effect with a total variance of $9.75 \pm 4.54 \%$ during the boreal summer. 


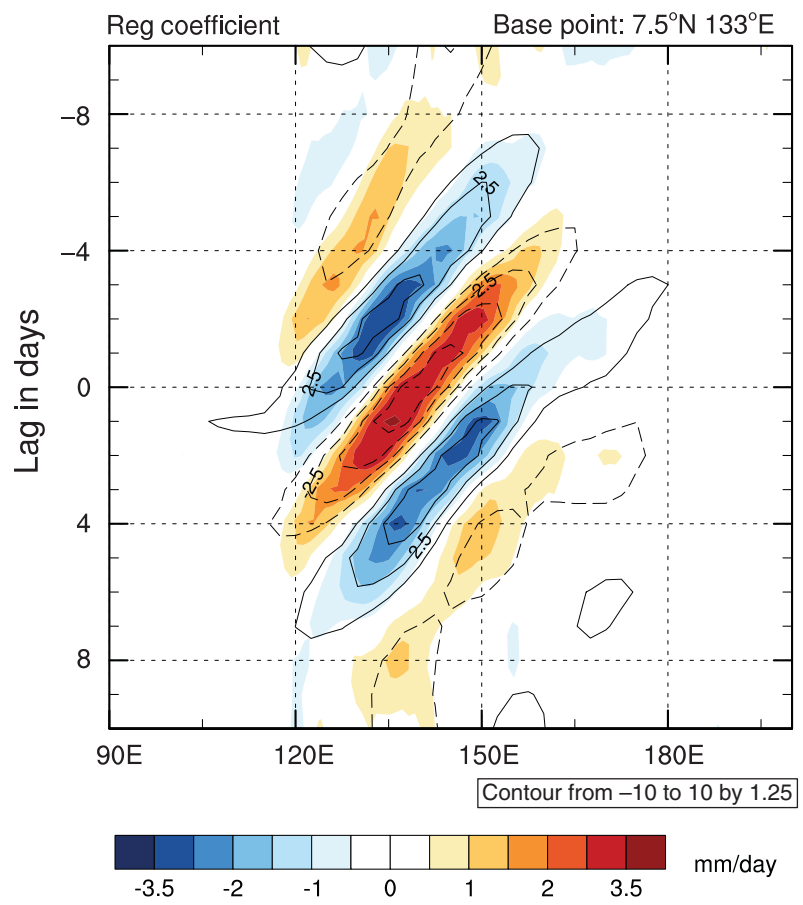

Figure 9. Similar to Figure 2, but for the regressed space-time evolution of precipitation associated with the TD-type waves at the base point $7.5^{\circ} \mathrm{N}, 133^{\circ} \mathrm{E}$.

To shed light on the area most affected by seasonal CCEW activity, spatial distribution based on the time of year when mean tropical convection is at its peak [i.e. extended boreal summer (MJJASO) and extended boreal winter (NDJFMA) seasons] is presented in Figure 13(a)-(h). The Kelvin waves are generally confined to the equatorial region, regardless of season (Figure 13(a) and (b)). The variance during boreal winter tends to reach its maximum, up to $15.02 \%$, covering the Atlantic Ocean, landmasses of western Africa, and the central Pacific near the date line. Apart from those regions, the Kelvin wave impact over the maritime continents of Africa, northern Australia, and South America is still evident, but to a lesser degree. During boreal summer, certain regions experience nearly identical effects from the Kelvin waves. Distinct differences are seen for the peak magnitude, in which it is generally decreased to $12.3 \%$ of the total variance and shifted northward off the equator. Profound seasonal activity of Kelvin waves, which appear similar to that of the ITCZ, suggests that these waves are likely generated in proximity to the most active convection, which happens to be located near the equator, much like the ITCZ cycle ( $c f$ Huang and Huang, 2011).

For ER waves, positively affected regions are evident away from the equator, at latitudes of maximum mean tropical convection $\left(12^{\circ}-15^{\circ}\right.$ latitude of the summer hemisphere) and with ratios around 8\% (Figure 13(c) and (d)). Stronger variances $(>7.5 \%)$ during boreal winter are mainly located over Australia, South Africa, and southern parts of the Maritime Continent, while during boreal summer they mostly covers the warm pool region of the western Pacific Ocean.
MRG and TD-type waves (Figure 13(e)-(h)) mainly affect the precipitation over the western North Pacific, eastern North Pacific (including Caribbean Sea), and Atlantic Basin (maximum peak in African West Coast) during boreal summer. These affected regions are known as those with the most active tracks of TCs, which in turn conforms that MRG and TD waves play an essential role to supply the rotational disturbances in the formation of TCs (cf Dickinson and Molinari, 2002; Schreck et al., 2012). During boreal winter, the peaks of MRG waves are more confined along the Pacific ITCZ (central and eastern Pacific basin at $7-10^{\circ} \mathrm{N}$ ) near the date line indicated by $5.5 \%$ of magnitude and the most enhanced variance mainly appears as a twin band along $7.5^{\circ} \mathrm{N}$ and $7.5^{\circ} \mathrm{S}$. TD-type waves, on the other hands, exhibit maximum impact over most regions of the southern Indian Ocean with ratios of $15-18 \%$ during boreal winter, while stronger ratios of $20-27 \%$ during boreal summer mainly affect the precipitation over the western North Pacific, eastern North Pacific, and Atlantic Ocean. This result is comparable with a previous study by Mekonnen et al. (2008) who showed, using a $\mathrm{Tb}$ dataset, that ratios of $25-30 \%$ cover most regions of summer convection over the ocean within the ITCZ. Overall, the strong seasonal variance contributed by TD-type activity suggests that they dominate precipitation variability over the tropics compared to other waves.

\subsection{Regional variation}

To further examine the seasonal influence of CCEW activity on a regional scale, the tropics have been divided into seven distinct regions similar as shown by Kim and Alexander (2013). These regions cover Africa $\left(17^{\circ} \mathrm{W}-50^{\circ} \mathrm{E}\right)$, the Indian Ocean $\left(51^{\circ} \mathrm{E}-94^{\circ} \mathrm{E}\right)$, the Maritime Continent $\left(95^{\circ} \mathrm{E}-150^{\circ} \mathrm{E}\right)$, the western Pacific $\left(151^{\circ} \mathrm{E}-150^{\circ} \mathrm{W}\right)$, the eastern Pacific $\left(149^{\circ} \mathrm{W}-90^{\circ} \mathrm{W}\right)$, America $\left(89^{\circ} \mathrm{W}-35^{\circ} \mathrm{W}\right)$, and the Atlantic Ocean $\left(34^{\circ} \mathrm{W}-18^{\circ} \mathrm{W}\right)$. The regional variances of four prominent waves (Kelvin, $n=1 \mathrm{ER}, \mathrm{MRG}$, and TD-type waves) as defined by the local integration of backward Fourier spectra in time are presented in Figure 14. The most obvious feature in this figure is that for each region in the tropics, TD-type waves have a much more significant impact on precipitation than any other wave type.

In Africa, TD-type waves exhibit a suppressed seasonal pattern from October to February, and become more active in summer, from July to September. The enhanced activity of TD-type waves during these periods corresponds to strong latent heating upstream, which is disrupted by the African Easterly Jet during the summertime (Thorncroft et al., 2008). This localized activity causes the TD-type waves to propagate until they reach the Atlantic Ocean. Kelvin waves also exhibit a similar seasonal cycle over Africa. The maximum activity appears during early boreal spring (March-April), with another peak occurs in August. This finding is consistent with Ventrice and Thorncroft (2013), who showed that the convective envelope of the Kelvin waves over the tropical Africa and 
(a) Lag: -1 days

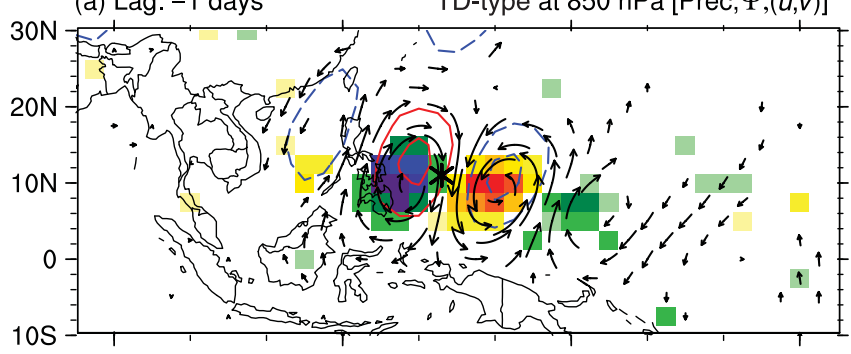

(b) Lag: 0 days

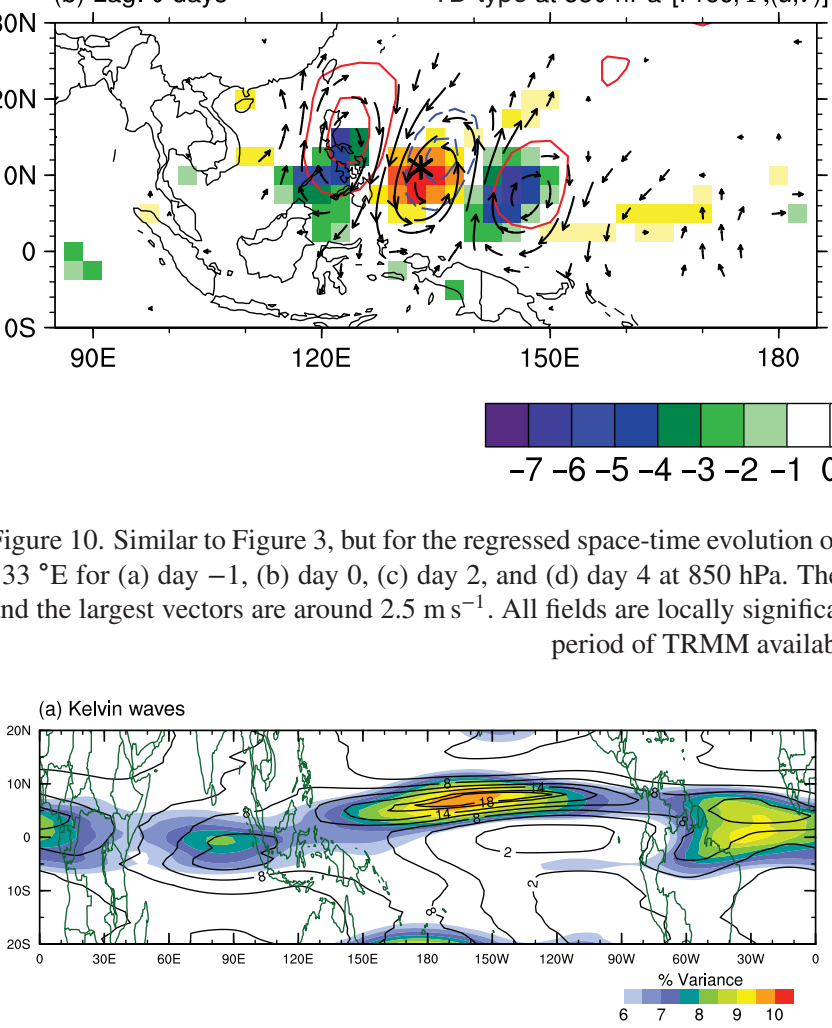

(c) ER waves

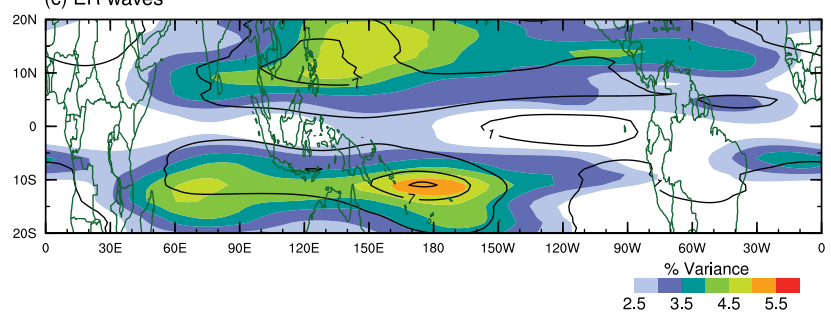

(c) Lag: 2 days

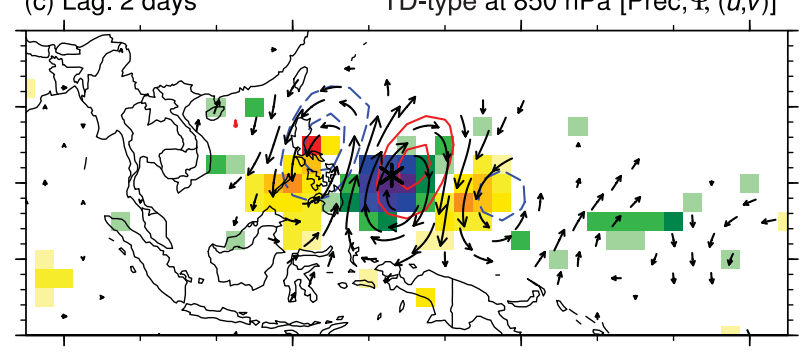

(d) Lag: 4 days

TD-type at $850 \mathrm{hPa}[\mathrm{Prec}, \Psi,(u, v)]$

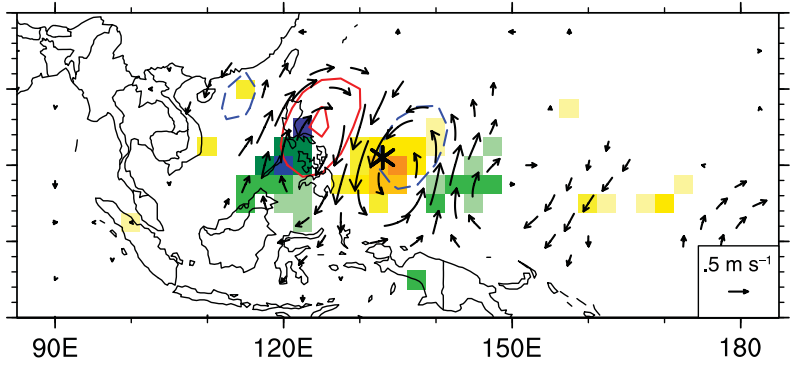

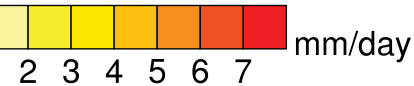

Figure 10. Similar to Figure 3, but for the regressed space-time evolution of precipitation associated with the TD-type waves at the base point $7.5^{\circ} \mathrm{N}$, $133^{\circ} \mathrm{E}$ for (a) day -1 , (b) day 0 , (c) day 2 , and (d) day 4 at $850 \mathrm{hPa}$. The contour increment for horizontal stream function $(\psi)$ is $5 \times 10^{5} \mathrm{~m}^{2} \mathrm{~s}^{-1}$ and the largest vectors are around $2.5 \mathrm{~m} \mathrm{~s}^{-1}$. All fields are locally significant at the $95 \%$ confidence level. This composite is calculated using entire period of TRMM available regardless of season.
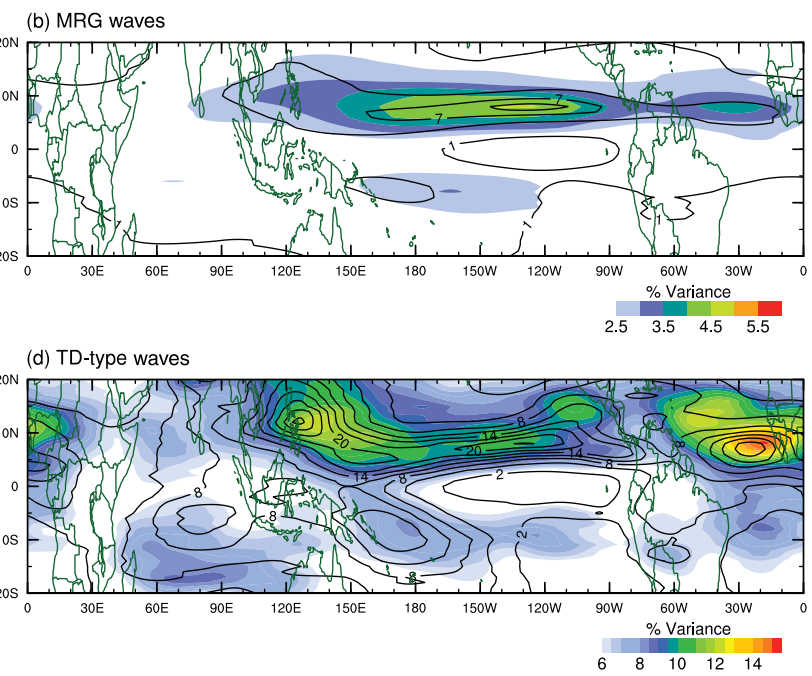

Figure 11. Fraction of the total precipitation variance that falls within the convectively coupled Kelvin, MRG, $n=1$ ER, and TD-type wave filter bands. Only Kelvin and TD-type waves (MRG and $n=1 \mathrm{ER}$ waves) with total variance $>6 \%(>2.5 \%)$ are shown with shading. The contour increment for the total variance is $3 \mathrm{~mm}^{2}$ day $^{-2}$.

Atlantic predominantly appears during boreal summer. Most easterly waves get an initial kick from convective events over the east African highlands, such as those that occur when Kelvin waves cross the region. Kelvin waves alter the synoptic background over tropical Africa and provide a favourable environment to support the genesis of TD-type waves. Therefore, a strongly enhanced activity of TD-type waves over this region is associated with the relatively enhanced Kelvin wave activity during boreal summer. Furthermore, the seasonal activity of MRG and ER waves remains approximately constant throughout the year. These results indicate that African precipitation variability is substantially controlled by TD-type waves during the summer time and is affected by Kelvin waves particularly during early boreal spring.

TD-type and Kelvin waves over America and the Atlantic Ocean have similar seasonal cycles as seen in Africa. Strong activity of TD-type waves prominently occurs in April and August, while the minimum activity occurs in May through June. The contribution of Kelvin waves during boreal winter is nearly twice as large as in summer. Enhanced activity over these regions is attributed 
(a) Kelvin
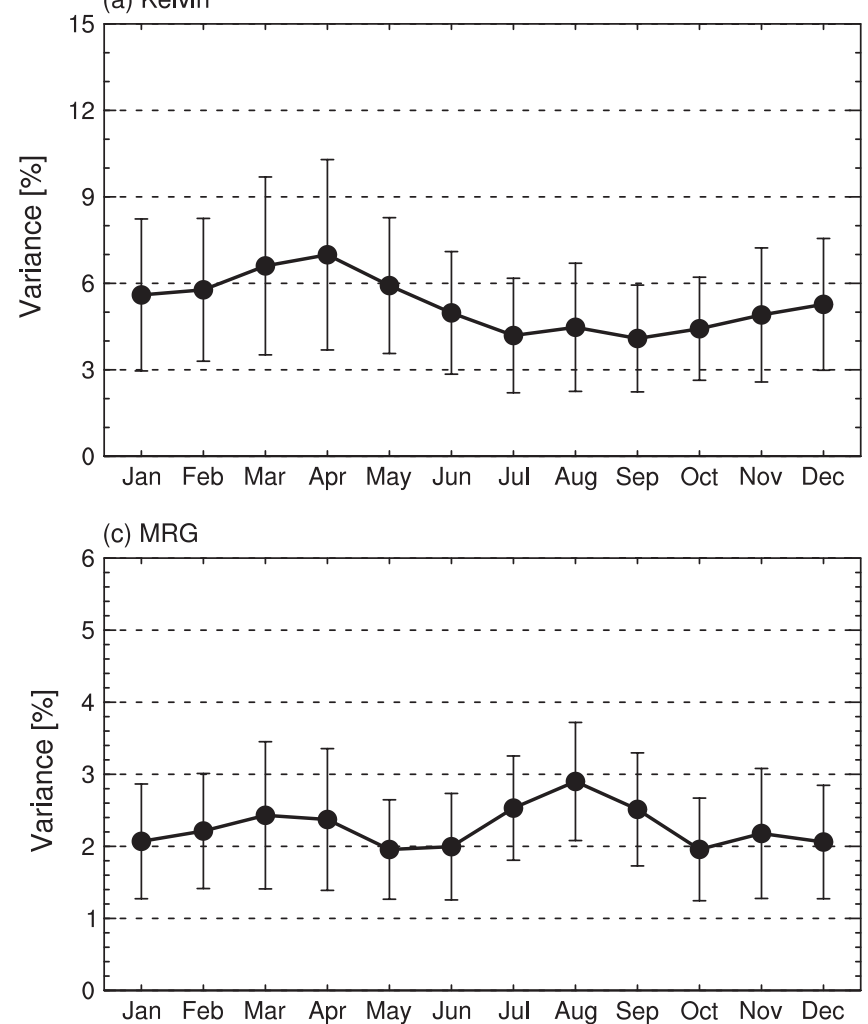

(b) $n=1 E R$

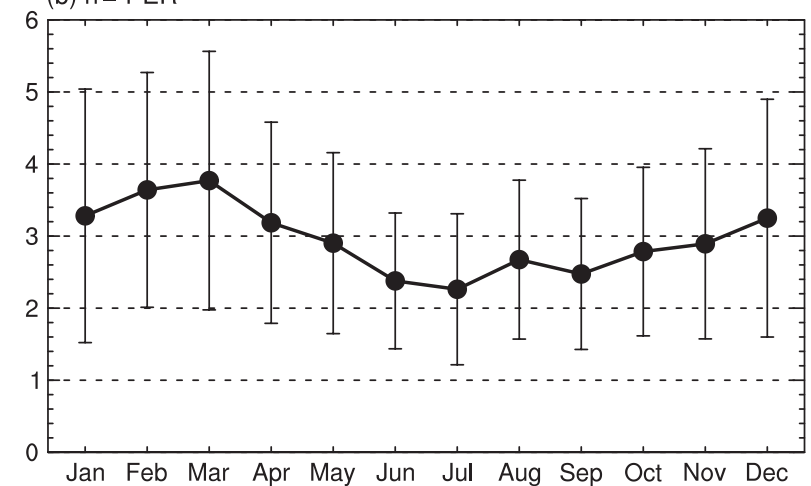

(d) TD-type

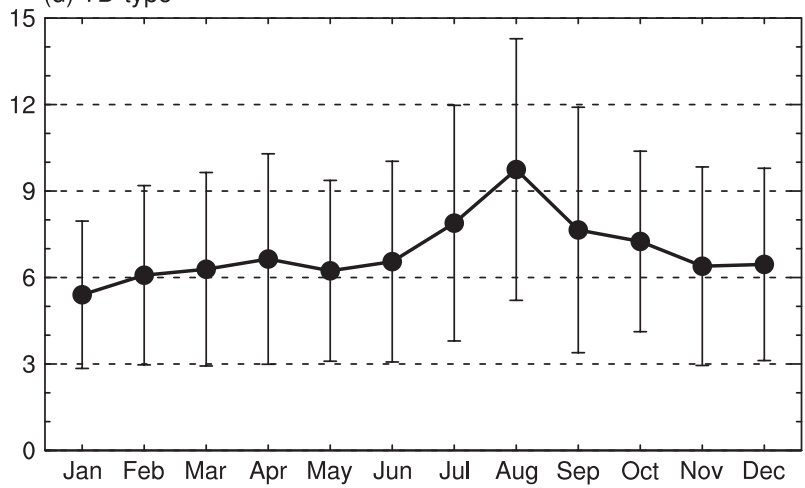

Figure 12. Seasonal cycle of CCEWs in fraction of the total precipitation variance $\left(\sigma^{2}\right)$ from 1998 through 2009 , averaged between $20^{\circ} \mathrm{N}$ and $20^{\circ} \mathrm{S}$ that falls within the Kelvin, MRG, ER, and Td-type waves filter band.

to the wave forcing within extratropical storms, particularly during boreal summer, and also corresponds to the latent heat release over Africa, which leads the wave propagation towards this region (e.g. Gu and Zhang, 2001; Thorncroft et al., 2008). Furthermore, the variability of both MRG and $n=1 \mathrm{ER}$ waves is similar to the variation over Africa.

The variance of TD-type waves and Kelvin waves over the western and eastern Pacific Ocean remains at nearly constant magnitude during boreal winter, but during boreal summer TD-type waves have a much higher contribution than Kelvin waves. Serra et al. (2008) demonstrated that strong latent heating through convection during boreal summer must be the primary energy source for Pacific TD-type waves, as there is much less horizontal and vertical shear in the basic state over the Pacific ITCZ. Impacts of $n=1$ ER and MRG waves on western Pacific precipitation are similar across all seasons, while over the eastern Pacific Ocean there seems to be more variation, with peak activity occurring during boreal winter. The cumulative activity of these four prominent waves during boreal winter may explain the strong synoptic to mesoscale convective precipitation over this region.

In the Maritime Continent, waves exhibit a similar seasonal cycle, except for the TD-type waves. These have twice the amplitude of MRG waves. Both of these waves are strongest during February to March and July to August. As mentioned in Section 4.2., relatively strong activity for TD-type and MRG waves within these periods is strongly manifested by the strengthening TC activities over the Philippine Sea and southern Indian Ocean. The eastward dispersion of Rossby wave energy emanating from these low latitude TCs provides sufficient energy to force these waves to propagate (Holland, 1995). Under the influence of an active monsoon system, the Maritime Continent will experience large convective activity owing to the water vapour carried by the winds from northern seas (north western Pacific and the South China Sea) to northern Australia. This in turn suggests an environment especially capable of exciting these waves within this period (December to April).

The appearance of strong seasonality of precipitation from the TD-type waves over the Indian Ocean is another problem concerning the spectral filter. Significant wave activity of this type is known to only be active in the tropical Pacific and Atlantic basins, and over Africa. So it may be assumed that such values are not contributed by TD-type waves, but they come from the strong background that happens to fall within the filter band. Furthermore, the MRG waves tend to have less seasonal effect on the local precipitation, as the variances mostly remain constant over all seasons. Furthermore, the $n=1$ ER waves have strong seasonal effects, with three peaks during boreal winter (December and February) and late boreal spring (May). The Kelvin wave activity shows in-phase seasonality as observed in the Maritime Continent, which suggests that the observed variance over the Maritime Continent is part of extended propagating variance initiated over 

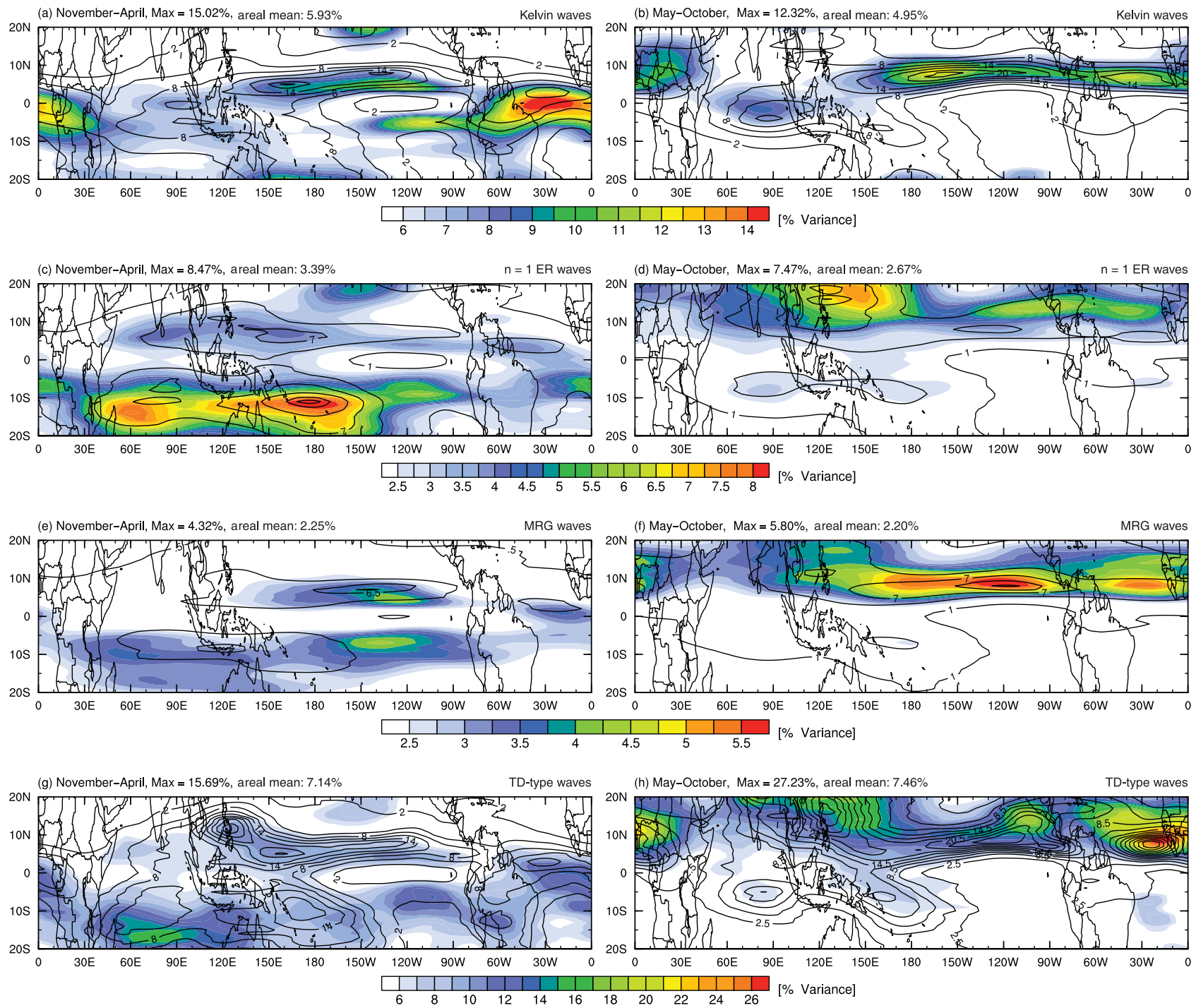

Figure 13. Fraction of the total precipitation variance during extended boreal winter (November to April) and extended boreal summer (May to October) that falls within the Kelvin, MRG, ER, and Td-type wave filter band. Note the different scaling of the colour bars. For Kelvin and TD-type waves (MRG and $n=1$ ER waves), only total variance $>6 \%(>2.5 \%)$ are shown with shading. The contour increment for the total variance is 3 $\mathrm{mm}^{2} \mathrm{day}^{-2}$.

the Indian Ocean. Strong interaction between MJO and Kelvin waves, and also the effect of the monsoon system on enhancing and terminating CCEWs, plays important roles in explaining the seasonal variability of precipitation over this region (Straub et al., 2006; Gloeckler and Roundy, 2013).

\section{Summary and concluding remarks}

We demonstrated the influence of CCEWs on the precipitation variability, retrieved from long-term observation of the TRMM merging high-quality/infrared (HQ/IR) precipitation. Since the wave-convection coupling manifests unique dispersion properties, a space-time filtering technique was used, and was tested against a randomly modulated periodic noise at a $95 \%$ confidence level. The geographical distribution of the locally most active wave amplitude variations was examined following Schreck et al. (2013), which allows estimating the fraction of the total variance contributed by a filter band at a given point.

The results show that CCEWs are unique in modulating precipitation over the tropics, and generally resemble equatorially trapped shallow water wave structures. The lower-level wave convergences were found to be a favourable location for precipitation, shedding light on the implications of wave-convection interaction. The precipitation resulting from Kelvin wave modulation exhibits an eastward phase progression with an average speed of $15.4 \mathrm{~m} \mathrm{~s}^{-1}$ and a practically symmetrical shape with respect to the equator. This slower phase speed is associated with a strong coupling interaction between waves and convection, as seen at shallower equivalent depths (WK99; Yang et al., 2007; Kiladis et al., 2009). Typical positive precipitation anomalies, which occur in the vicinity of the maximum lower-level wind convergence and to the east of the positive geopotential height anomalies, conform to the typical Kelvin wave structure predicted 

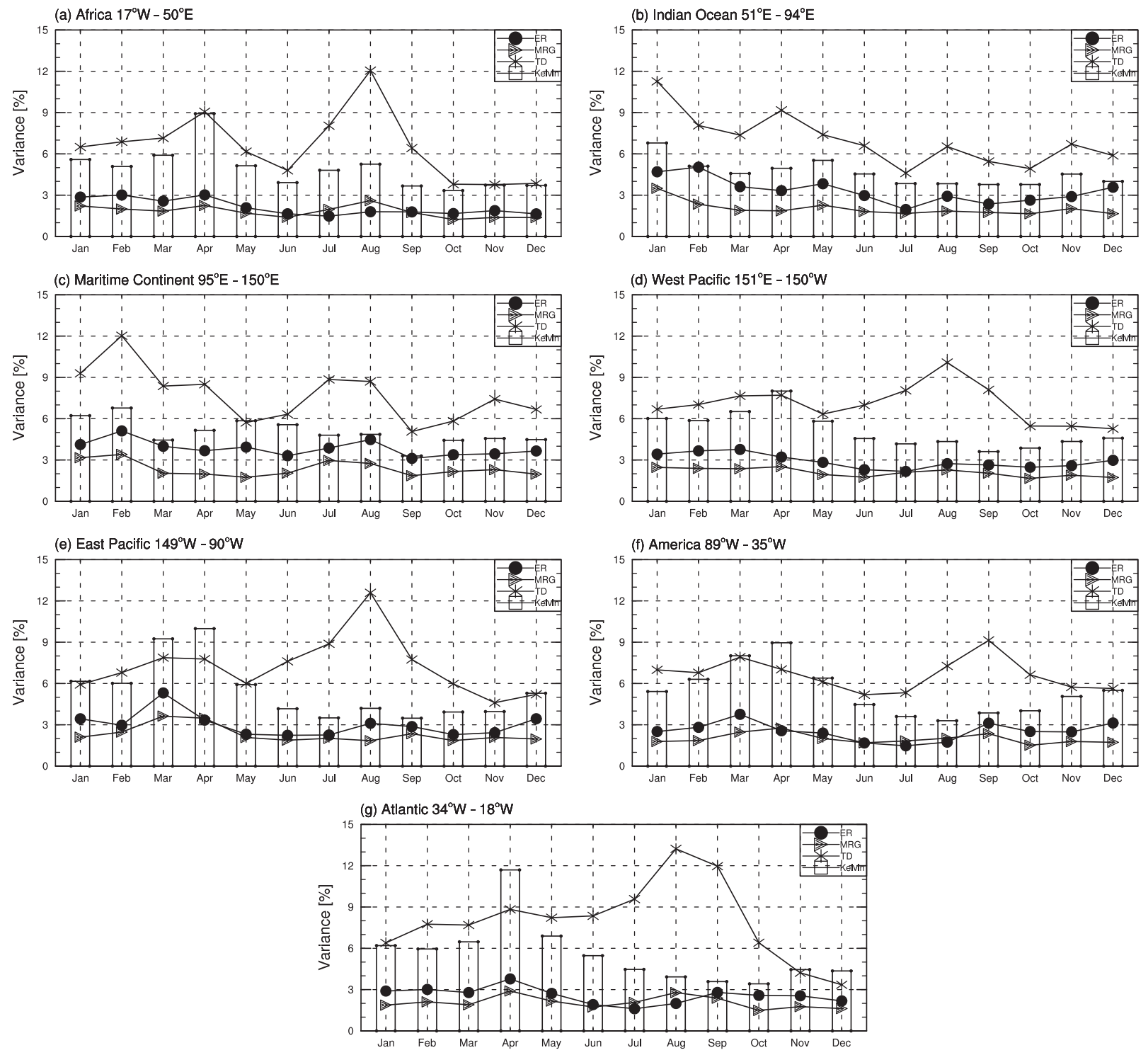

Figure 14. Fraction of the total precipitation variance (\%) attributed to seasonal cycle of CCEW activity in (a) Africa, (b) Indian Ocean, (c) Maritime Continent, (d), West Pacific, (e) East Pacific, (f) America, and (g) Atlantic, from 1998 through 2009 and averaged between $20^{\circ} \mathrm{N}$ and $20^{\circ} \mathrm{S}$.

by Matsuno (1966). Furthermore, we also found that strong interferences of Southern Hemisphere extratropical Rossby waves on the Kelvin wave structures appear significantly during boreal summer over the eastern Pacific. The poleward flow from the Kelvin wave structure, which is likely a part of the eastward-propagating Rossby wave train response to convective heating in tropics is evident as found by Straub and Kiladis (2002). This poleward flow is strongly linked with the Kelvin wave troughs and plays a substantial role in transporting equatorial humid air towards the off-equatorial region (Figure 3(a)-(d), $c f$ Masunaga, 2009). On the other hand, the equatorward flows emanated from extratropical Rossby wave trains are found to contribute to positive moisture anomalies in the equatorial Kelvin wave structure (Figure 3(e) and (f)). During the boreal winter, however, the compositing fields at the upper level are dominated by a Rossby wave structure propagating into the eastern tropical Pacific from the mid-latitudes. This intertwined pattern of Kelvin and
Rossby waves must be considered as a result of contaminating the Kelvin-filter band by eastward moving deep convection and upper clouds signal forced dominantly during boreal winter-spring ( $c f$ Kiladis, 1998; Schreck et al., 2013). This is a good example of how the filtering can be misleading, and showing the importance of interpreting the resulting filter band carefully, and with appropriate metrics.

Modulated precipitation by ER waves shows a slower westward phase progression with symmetric pairs of off-equatorial maxima, and a weak equatorial peak near the equator. The convective signal indicated by positive precipitation anomalies is displaced to the east of the cyclonic gyres. This modulated behaviour is consistent with the convectively coupled ER wave structure discussed by Wheeler et al. (2000). The appearance of a Kelvin-like pattern with predominant easterly winds to the east of the convective centre and locally low pressures on the equator (Figure 6(a)-(d)) may suggest a possibility of triggering 
mechanism from Kelvin waves forced by equatorial heating (cf Gill, 1980; Kiladis et al., 2009). However, we did not further explore this triggering evidence closely, as it is beyond the scope of this current study. We also showed that the modulated precipitation pattern from ER waves seems to shift to around $10^{\circ} \mathrm{N}$ as they reach the region of New Guinea. This modulated behaviour is likely related to the strengthening of westward propagating monsoon gyres and TC activity over the western North Pacific and Asia (cf Yokoi and Satomura, 2005; Straub et al., 2006; Schreck et al., 2012). Nevertheless, the detailed mechanisms underlying this phenomenon are not yet clearly understood. On the other hand, this evidence also suggests that precipitation over Asia is more affected by ER wave activity compared with northern Australia, which is consistent with findings of Kiladis et al. (2009) using $\mathrm{Tb}$ composites.

Concerning MRG waves, we showed that precipitation is modulated asymmetrically to the west and concurrently followed by symmetrical gyres. The modulation is primarily located slightly away from the equator, which agrees with findings from studies by Zangvil and Yanai (1980), and Hendon and Liebmann (1991), who pointed out that the peak of modulated convection primarily occurs around $7.5^{\circ}$ latitude. On the other hand, the precipitation resulting from TD-type waves is tightly excited within the trough axis of off-equatorial lower vortex trains. The troughs of TD-type vortex trains are a preferred zone to induce precipitation in which the strong convection excited by vortical flow may occur favourably (cf Takayabu and Nitta, 1993). The modulated envelopes move diagonally westward with a phase progression of about $-9.5 \mathrm{~m} \mathrm{~s}^{-1}$.

The current study also specifically quantifies for the first time the impacts of Kelvin, $n=1 \mathrm{ER}, \mathrm{MRG}$, and TD-type waves on precipitation, in terms of seasonal and regional variations from long-term observation of TRMM satellite data. Variability of tropical precipitation due to CCEWs behaves relatively varied depending on season and geographical region. Our analysis shows that the portion of daily precipitation associated with the positive phase of Kelvin waves occurs predominantly during boreal spring; during which maximum impacts are present from March to May, with the largest value of $6.99 \pm 3.30 \%$ of the total precipitation variance in the tropics $\left(20^{\circ} \mathrm{N}-20^{\circ} \mathrm{S}\right)$. Most active Kelvin-precipitation variance during this period is primarily caused by strong convection activity near the equator. On the other hand, the westward high precipitation variance of $n=1$ ER waves mainly take place during late boreal winter, with a maximum of $3.77 \pm 1.79 \%$ (1-2 months earlier than the Kelvin wave peak). The modulating precipitation is confined to the area over $12^{\circ}-15^{\circ}$ latitude, and predominantly affects the Asian monsoon region and south-western Pacific Ocean. Our results also show that along with strong convection activity, the enhanced variance of Kelvin and $n=1$ ER waves during boreal winter are also strongly affected by extratropical wave forcing, during which the northern basic state facilitates more equatorward propagation of extratropical waves.
TD-type waves' impact on precipitation is predominantly higher than MRG waves during boreal summer, and they account for up to $9.75 \pm 4.54 \%$ of the total precipitation variance in August, which is three times higher than the one of the MRG peak $(2.90 \pm 0.82 \%)$. Relatively strong activity of these waves in modulating precipitation during boreal summer occurs because they are often forced as part of the eastward-dispersion of energy from low latitude TCs over the western Pacific (cf Frank and Roundy, 2006), which are more common during the boreal summer and fall. Moreover, in Africa, TD-type waves are predisposed to periods of time when the positive poleward temperature gradient and low-level easterly jets are present (Frank and Roundy, 2006; Leroux and Hall, 2009). However, it should be noted that the strong seasonality of precipitation due to TD-type waves over the Indian Ocean is not directly associated with TD-type activity, but comes from the strong background that falls within the filter band. In addition, MRG waves are found to be profoundly most active over the Western/ Central Pacific during boreal summer-fall, particularly due to a supplied energy from a broad poleward potential vorticity gradient (Frank and Roundy, 2006).

Overall, our results suggest that although being less dominant than other different timescales of tropical oscillation (e.g. gravity waves, ENSO, and MJO), these four types of CCEWs can considerably influence tropical precipitation variability during boreal summer (mainly due to the enhanced activity of MRG and TD-type waves) and boreal winter (due to Kelvin and $n=1$ ER waves). Understanding the potential impact of CCEWs on precipitation definitely provides a substantial key for improving the predictability of precipitation both on synoptic and longer timescales. More work, however, is still needed to further investigate the other possible mechanistic processes, such as wave-mean flow interaction in inducing the tropical precipitation.

\section{Acknowledgements}

The 3B42 v.6 TRMM merged HQ/IR precipitation products were supplied by Goddard Space Flight Center (GSFC) National Aeronautics and Space Administration (NASA), USA, at http://trmm.gsfc.nasa.gov/. The authors also would like thank NOAA/NESDIS and NCEP/NCAR for providing the satellite and reanalysis data in the study. The stay of the first author at University of Leipzig was fully supported by the Directorate General of Higher Education (DIKTI), Department of National Education of the Republic of Indonesia. The authors are grateful to three anonymous reviewers for helping to improve the manuscript.

\section{Supporting Information}

The following supporting information is available as part of the online article:

Figure S1. Wavenumber-frequency spectra of TRMM daily precipitation for winter 1998 to 2009. 
Figure S2. As in Figure S1, but for spring.

Figure S3. As in Figure S1, but for summer.

Figure S4. As in Figure S1, but for fall.

Figure S5. Lagged composite of precipitation (shading), geopotential height (contours), and wind (vectors) associated with Kelvin-wave-filtered time series of precipitation at $850 \mathrm{hPa}$ during DJF. All fields are locally significant at the $95 \%$ confidence level.

Figure S6. As in Figure S5, but for MAM.

Figure S7. As in Figure S5, but for SON.

Figure S8. As in Figure S5, but for JJA.

Figure S9. As in Figure S5, but for DJF at $200 \mathrm{hPa}$.

Figure S10. As in Figure S5, but for MAM at $200 \mathrm{hPa}$.

Figure S11. As in Figure S5, but for JJA at $200 \mathrm{hPa}$.

Figure S12. As in Figure S5, but for SON at $200 \mathrm{hPa}$.

Figure S13. Lagged composite of precipitation (shading), geopotential height (contours), and wind (vectors) associated with $n=1$ ER-wave-filtered time series of precipitation at $850 \mathrm{hPa}$ during DJF. All fields are locally significant at the $95 \%$ confidence level.

Figure S14. As in Figure S13, but for MAM.

Figure S15. As in Figure S13, but for JJA.

Figure S16. As in Figure S13, but for SON.

Figure S17. Lagged composite of precipitation (shading), geopotential height (contours), and wind (vectors) associated with MRG-wave-filtered time series of precipitation at $850 \mathrm{hPa}$ during DJF. All fields are locally significant at the $95 \%$ confidence level.

Figure S18. As in Figure S17, but for MAM.

Figure S19. As in Figure S17, but for JJA.

Figure S20. As in Figure S17, but for SON.

Figure S21. Lagged composite of precipitation (shading), geopotential height (contours), and wind (vectors) associated with TD-type-wave-filtered time series of precipitation at $850 \mathrm{hPa}$ during DJF. All fields are locally significant at the $95 \%$ confidence level.

Figure S22. As in Figure S21, but for MAM.

Figure S23. As in Figure S21, but for JJA.

Figure S24. As in Figure S21, but for SON.

\section{References}

Cho HK, Bowman KP, North GR. 2004. Equatorial waves including the Madden-Julian oscillation in TRMM rainfall and OLR data. J. Clim. 17: 4387-4407, DOI: $10.1175 / 3215.1$

Dickinson M, Molinari J. 2002. Mixed Rossby-gravity waves and Western Pacific tropical cyclogenesis. Part I: Synoptic evolution. J. Atmos. Sci. 59: 2183-2196, DOI: 10.1175/1520-0469(2002)059< 2183:MRGWAW>2.0.CO;2.

Frank WM, Roundy PE. 2006. The role of tropical waves in tropical cyclogenesis. Mon. Weather Rev. 134: 2397-2417, DOI: 10.1175/ MWR3204.1.

Gill AE. 1980. Some simple solutions for heat-induced tropical circulation. Q. J. R. Meteorol. Soc. 106: 447-462, DOI: 10.1002/ qj.49710644905.

Gloeckler LC, Roundy PE. 2013. Modulation of the extratropical circulation by combined activity of the Madden-Julian oscillation and equatorial Rossby waves during boreal winter. Mon. Weather Rev. 141: 1347-1357, DOI: 10.1175/MWR-D-12-00179.1.

Gu G, Zhang C. 2001. A spectrum analysis of synoptic-scale disturbances in the ITCZ. J. Clim. 14: 2725-2739, DOI: 10.1175/15200442(2001)014<2725:ASAOSS>2.0.CO; 2.

Hendon HH, Liebmann B. 1991. The Structure and annual variation of antisymmetric fluctuations of tropical convection and their association with Rossby-gravity waves. J. Atmos. Sci. 48: 2127-2140, DOI: 10.1175/1520-0469(1991)048<2127:TSAAVO>2.0.CO;2.

Holder CT, Yuter SE, Sobel AH, Aiyyer AR. 2008. The mesoscale characteristics of tropical oceanic precipitation during Kelvin and mixed Rossby-gravity wave events. Mon. Weather Rev. 136: 3446-3464, DOI: 10.1175/2008MWR2350.1.

Holland GJ. 1995. Scale interaction in the western Pacific monsoon. Meteorol. Atmos. Phys. 56: 57-59, DOI: 10.1007/BF01022521.

Hoskins BJ, Yang GY. 2000. The equatorial response to higher latitude forcing. J. Atmos. Sci. 57: 1197-1213, DOI: 10.1175/15200469(2000)057<1197:TERTHL>2.0.CO;2.

Huang P, Huang RH. 2011. Climatology and interannual variability of convectively coupled equatorial wave activity. J. Clim. 24: 4451-4465, DOI: 10.1175/2011JCLI4021.

Huffman GJ, Adler RF, Bolvin DT, Gu G, Nelkin EJ, Bowman KP, Hong Y, Stocker EF, Wolff DB. 2007. The TRMM Multi-satellite Precipitation Analysis (TMPA): quasi-global, multi-year, combined-sensor precipitation estimates at fine scale. J. Hydrometeorol. 8: 38-55, DOI: 10.1175/JHM560.1.

Kanamitsu M, Ebisuzaki W, Woollen J, Yang SK, Hnilo JJ, Fiorino M, Potter GL. 2002. NCEP/DOE AMIP-II reanalysis. Bull. Am. Meteorol. Soc. 83: $1631-1643$.

Kawatani Y, Takahashi M, Sato K, Alexander SP, Tsuda T. 2009. Global distribution of atmospheric waves in the equatorial upper troposphere and lower stratosphere: AGCM simulation of sources and propagation. J. Geophys. Res. 114, DOI: 10.1029/2008 JD010374.

Kiladis GN. 1998. Observations of Rossby waves linked to convection over the eastern tropical Pacific. J. Atmos. Sci. 55: 321-339, DOI: 10.1175/1520-0469(1998)055<0321:OORWLT > 2.0.CO; 2.

Kiladis G, Wheeler M. 1995. Horizontal and vertical structure of observed tropospheric equatorial Rossby waves. J. Geophys. Res. 100: 22981-22997, DOI: 10.1029/95JD02415.

Kiladis GN, Thorncroft CD, Hall NMJ. 2006. Three dimensional structure and dynamics of African easterly waves. Part I: Observations. J. Atmos. Sci. 63: 2212-2230, DOI: 10.1175/JAS3741.1.

Kiladis G, Wheeler M, Haertel P, Straub K, Roundy P. 2009. Convectively coupled equatorial waves. Rev. Geophys. 47: RG2003, DOI: 10.1029/2008RG000266.

Kim J, Alexander M. 2013. Tropical precipitation variability and convectively coupled equatorial waves on submonthly time-scales in reanalyses and TRMM. J. Clim. 26: 3013-3030, DOI: 10.1175/ JCLI-D-12-00353.1.

Kim D, Lee M-I, Kim D, Schubert SD, Waliser DE, Tian B. 2013. Representation of tropical subseasonal variability of precipitation in global reanalyses. Clim. Dyn., DOI: 10.1007/s00382-013-1890.

Leroux S, Hall NMJ. 2009. On the relationship between African easterly waves and the African easterly jet. J. Atmos. Sci. 66: 2303-2316, DOI: 10.1175/2009JAS2988.1.

Li R, Fu Y. 2005. Tropical precipitation estimated by GPCP and TRMM PR observations. Adv. Atmos. Sci. 22: 852-864.

Liebmann B, Smith CA. 1996. Description of a complete (interpolated) OLR dataset. Bull. Am. Meteorol. Soc. 77: 1275-1277.

Liebmann B, Kiladis GN, Carvalho LMV, Jones C, Vera CS, Blade I, Allured D. 2009. Origin of convectively coupled Kelvin waves over South America. J. Clim. 22: 300-315, DOI: 10.1175/ 2008JCLI2340.1.

Lin JL Kiladis GN, Mapes BE, Weickmann KM, Sperber KR, Lin W, Wheeler MC, Schubert SD, Genio AD, Donner LJ, Emori S, Gueremy JF, Hourdin F, Rasch PJ, Roeckner E, Scinocca JF. 2006. Tropical intraseasonal variability in 14 IPCC AR4 climate models. Part I: Convective signals. J. Clim. 19: 2665-2690, DOI: 10.1175/JCLI3735.1.

Lindzen RS. 1974. Wave-CISK in the tropics. J. Atmos. Sci. 31: 156-179, DOI: 10.1175/1520-0469(1974)031<0156:WCITT $>2.0$. $\mathrm{CO} ; 2$.

Lindzen RS. 2003. The interaction of waves and convection in the tropics. J. Atmos. Sci. 60: 3009-3020, DOI: 10.1175/1520-0469(2003) $060<3009$ :TIOWAC $>2.0 . \mathrm{CO} ; 2$.

Masunaga H. 2009. A 9-season TRMM observation of the Austral summer MJO and low-frequency equatorial waves. J. Meteorol. Soc. Jpn. 87: 295-315.

Masunaga H, L'Ecuyer TS, Kummerow CD. 2006. The Madden-Julian oscillation recorded in early observations from the Tropical Rainfall Measuring Mission (TRMM). J. Atmos. Sci. 63: 2777-2794, DOI: 10.1175/JAS3783.1.

Matsuno T. 1966. Quasi-geostrophic motions in the equatorial area. $J$. Meteorol. Soc. Jpn. 44: 25-43. 
Maury P, François L, Lionel G, Jean-Philippe D. 2013. Tropical variability and stratospheric equatorial waves in the IPSLCM5 model. Clim. Dyn. 40: 2331-2344.

Meehl GA, Kiladis GN, Weickmann KM, Wheeler M, Gutzler DS, Compo GP. 1996. Modulation of equatorial subseasonal convective episodes by tropical-extratropical interaction in the Indian and Pacific Ocean regions. J. Geophys. Res. 101: 15033-15049, DOI: 10.1029/96JD01014.

Mekonnen A, Thorncroft CD, Aiyyer A. 2006. Analysis of convection and its association with African easterly waves. J. Clim. 19: 5405-5421, DOI: 10.1175/JCLI3920.1.

Mekonnen A, Thorncroft CD, Aiyyer A, Kiladis GN. 2008. Convectively coupled Kelvin waves over tropical Africa during the boreal summer: structure and variability. J. Clim. 21: 6649-6667, DOI: 10.1175/2008JCLI2008.1.

Mounier F, Kiladis GN, Janicot S. 2007. Analysis of the dominant mode of convectively coupled Kelvin waves in the West African Monsoon. J. Clim. 20: 1487-1503, DOI: 10.1175/JCLI4059.1.

Press WH, Teukolsky SA, Vetterling WT, Flannery BP. 1986. Numerical Recipes: The Art of Scientific Computing. Cambridge University Press: New York, NY, xi, ISBN 0-521-30811-9.

Roundy P, Frank W. 2004. A climatology of waves in the equatorial region. J. Atmos. Sci. 61: 2105-2132, DOI: 10.1175/15200469(2004)061<2105:ACOWIT>2.0.CO;2.

Salby ML, Garcia RR, Hendon HH. 1994. Planetary-scale circulations in the presence of climatological and wave-induced heating. J. Atmos. Sci. 51: 2344-2367, DOI: 10.1175/1520-0469(1994) 051;2<2344:PSCITP $>2.0 . \mathrm{CO}$

Schreck CJ, Molinari J, Aiyyer A. 2012. A global view of equatorial waves and tropical cyclogenesis. Mon. Weather Rev. 140: 774-788, DOI: 10.1175/MWR-D-11-00110.1.

Schreck CJ, Shi L, Kossin JP, Bates JJ. 2013. Identifying the MJO, equatorial waves, and their impacts using 32 years of HIRS upper tropospheric water vapor. J. Clim. 26: 1418-1431, DOI: 10.1175/JCLID-12-00034.1.

Serra YL, Kiladis GN, Cronin MF. 2008. Horizontal and vertical structure of easterly waves in the Pacific ITCZ. J. Atmos. Sci. 65 1266-1284, DOI: 10.1175/2007JAS2341.1.

Sobel AH, Yuter SE, Bretherton CS, Kiladis GN. 2004. Large-scale meteorology and deep convection during TRMM KWAJEX. Mon. Weather Rev. 132: 422-444, DOI: 10.1175/1520-0493(2004)132< 0422:LMADCD>2.0.CO;2.

Straub KH, Kiladis GN. 2002. Observations of a convectively coupled Kelvin wave in the Eastern Pacific ITCZ. J. Atmos. Sci. 59: 30-53, DOI: 10.1175/1520-0469 (2002)059<0030:OOACCK>2.0.CO;2.

Straub KH, Kiladis GN. 2003. Extratropical forcing of convectively coupled Kelvin waves during austral winter. J. Atmos. Sci. 60: 526-543, DOI: 10.1175/1520-0469(2003)060<0526:EFOCCK >2.0.CO;2.

Straub KH, Kiladis GN, Ciesielski PE. 2006. The role of equatorial waves in the onset of the South China Sea summer monsoon and the demise of El Nino during 1998. Dyn. Atmos. Oceans 42: 216-238, DOI: 10.1016/j.dynatmoce.2006.02.005.

Takayabu YN. 1994. Large-scale cloud disturbances associated with equatorial waves I: spectral features of the cloud disturbances. $J$. Meteorol. Soc. Jpn. 72: 433-449.

Takayabu YN, Nitta TS. 1993. 3-5 day-period disturbances coupled with convection over the tropical Pacific Ocean. J. Meteorol. Soc. Jpn. 71: $221-246$.

Thorncroft CD, Hall NMJ, Kiladis GN. 2008. Three dimensional structure and dynamics of African easterly waves. Part III: Genesis. J. Atmos. Sci. 65: 3596-3607, DOI: 10.1175/2008JAS2575.1.

Ventrice VJ, Thorncroft CD. 2013. The role of convectively coupled atmospheric Kelvin waves on African easterly wave activity. Mon. Weather Rev. 141: 1910-1924, DOI: 10.1175/MWR-D-12-00147.1.

Wheeler M, Kiladis GN. 1999. Convectively coupled equatorial waves: analysis of clouds and temperature in the wavenumber-frequency domain. J. Atmos. Sci. 56: 374-399, DOI: 10.1175/1520-0469(1999) 056<0374:CCEWAO > 2.0.CO;2.

Wheeler M, Weickmann KM. 2001. Real-time monitoring and prediction of modes of coherent synoptic to intraseasonal tropical variability. Mon. Weather Rev. 129: 2677-2694, DOI: 10.1175/1520-0493 (2001) $129<2677:$ RTMAPO $>2.0 . C O ; 2$.

Wheeler M, Kiladis GN, Webster PJ. 2000. Large-scale dynamical fields associated with convectively coupled equatorial waves. $J$. Atmos. Sci. 57: 613-640, DOI: 10.1175/1520-0469(2000)057<0613: LSDFAW $>2.0 . \mathrm{CO} ; 2$.

Yang GY, Hoskins BJ, Slingo JM. 2003. Convectively coupled equatorial waves: a new methodology for identifying wave structures in observational data. J. Atmos. Sci. 60: 1637-1654, DOI: 10.1175/ 1520-0469(2003)060<1637:CCEWAN>2.0.CO;2.

Yang GY, Hoskins BJ, Slingo JM. 2007. Convectively coupled equatorial waves. Part I: Horizontal and vertical structures. J. Atmos. Sci. 64: 3406-3423, DOI: 10.1175/JAS4017.1.

Yang GY, Hoskins BJ, Slingo JM. 2011. Equatorial waves in opposite QBO phases. J. Atmos. Sci. 68: 839-862, DOI: 10.1175/ 2010JAS3514.1.

Yang GY, Hoskins BJ, Gray L. 2012. The influence of the QBO on the propagation of equatorial waves into the stratosphere. J. Atmos. Sci. 69: 2959-2982, DOI: 10.1175/JAS-D-11-0342.1.

Yokoi S, Satomura T. 2005. An observational study of intraseasonal variations over Southeast Asia during the 1998 rainy season. Mon. Weather Rev. 133: 2091-2104, DOI: 10.1175/MWR2967.1.

Zangvil A, Yanai M. 1980. Upper tropospheric waves in the tropics. Part I: Dynamical analysis in the wavenumber-frequency domain. J. Atmos. Sci. 37: 283-298, DOI: 10.1175/1520-0469(1980)037 $<0283$ :UTWITT $>2.0 . \mathrm{CO} ; 2$

Zwiers FW, von Storch H. 1995. Taking serial correlation into account in tests of the mean. J. Clim. 8: 336-351. 